\title{
Subject responses to electrochromic windows
}

\author{
R.D. Clear ${ }^{*}$, V. Inkarojrit, E.S. Lee \\ Building Technologies Program, Environmental Energy Technologies Division, Lawrence Berkeley \\ National Laboratory, Mailstop 90-3111, 1 Cyclotron Road, Berkeley, CA 94720, USA
}

\begin{abstract}
Forty-three subjects worked in a private office with switchable electrochromic windows, manuallyoperated Venetian blinds, and dimmable fluorescent lights. The electrochromic window had a visible transmittance range of approximately 3-60\%. Analysis of subject responses and physical data collected during the work sessions showed that the electrochromic windows reduced the incidence of glare compared to working under a fixed transmittance $(60 \%)$ condition. Subjects used the Venetian blinds less often and preferred the variable transmittance condition, but used slightly more electric lighting with it than they did when window transmittance was fixed.
\end{abstract}

Keywords: Electrochromic windows, Venetian blind use, subjective response, energy use

\section{Introduction}

Electrochromic windows exhibit a change in transmission while maintaining a transparent view when a small dc-voltage is applied to the window. Products are beginning to be introduced to the market. Although conventional windows are generally viewed favorably by occupants, they sometimes allow too much light, along with associated glare and excessive heat, to enter the space. Traditional methods for controlling the amount of light entering the space, such as shades or blinds, generally block the view as well, and may be awkward to control. Electrochromic windows provide a light control solution that avoids these problems. However, current electrochromic windows have potential problems of their own. The electrochromic windows we tested have a visible transmittance range which is limited to approximately $3 \%$ to $60 \%$. Even 3\% transmittance may not be low enough to control glare and direct sun, while higher transmittances are desirable for daylight harvesting and view under lower light conditions [1,2]. The windows we tested are fairly small in size (approximately 0.9 meters on the long side), change color as their transmittance changes, and take several minutes to change their transmittance over their full range. Larger electrochromic windows have been made, but not with such a wide transmittance range. No current electrochromic window has any directional properties. A blind can be tilted to block direct sun, while still allowing a partial view. Electrochromic windows reduce the transmission of light from all directions.

Electrochromic windows are an emerging technology and little has been published about their acceptability $[3,4]$. This research project was designed to answer several questions. The first was whether an office with electrochromic windows and blinds provides an acceptable and satisfactory work environment. The second was to determine whether, and under what conditions, the use of blinds is reduced. The third was to compare the operation of, and satisfaction with, two different control methods (algorithms) for the electrochromic windows. A final goal was to examine the energy and power use of electrochromic windows as compared to a standard window.

\footnotetext{
* Corresponding author: Tel.: +1-510-486-4286; fax: +1-510-486-4089. Email address: rdclear@lbl.gov (R.D.Clear).
} 


\section{Experimental setup}

Electrochromic windows were installed in two rooms in the window systems testbed facility at the Lawrence Berkeley National Laboratory (LBNL) in Berkeley, California (latitude $37^{\circ} 4^{\prime}$ north). Both rooms were $3 \mathrm{~m}$ wide by $4.6 \mathrm{~m}$ deep and $3.4 \mathrm{~m}$ high (Figure 1). The south wall of the rooms had electrochromic windows installed in a 3 unit wide by 5 unit high window grid, that ran from wall to wall, and from about $34 \mathrm{~cm}$ above the floor to a height of approximately $2.7 \mathrm{~m}$. Each of the three window columns also had an operable Venetian blind $(91.4 \mathrm{~cm}$ wide by $295 \mathrm{~cm}$ long with a $2.5 \mathrm{~cm}$ curved aluminum slat of matte white color). The mullions between the windows were approximately $7.6 \mathrm{~cm}$ wide and $6.35 \mathrm{~cm}$ high. The north wall contained a door and the other two walls were blank. The room contained desks along the south and west walls. A computer was placed on the west wall desk.

The lighting and control equipment and most of the physical monitoring of the testbed facility have been described in a previous paper [5]. Measurements included outdoor and indoor light measurements, outdoor irradiance, equipment wattages, control system data, and transmittance measurements of the windows. For this study, we added the Venetian blinds, and monitoring equipment to measure blind height and tilt. We also added indoor vertical illuminance and luminance sensors. All data was sampled and recorded at one minute intervals.
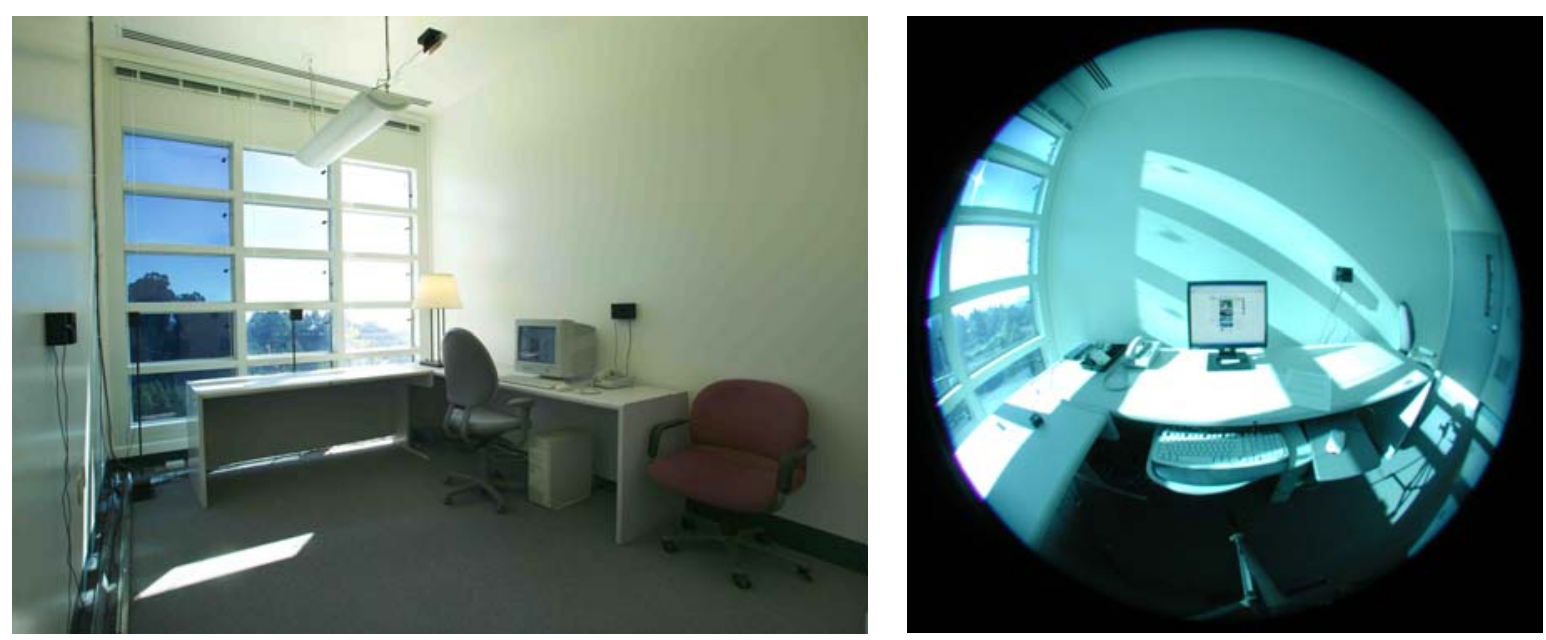

Fig. 1. Perspective (left) and fisheye (right) of test room interior. The left view shows the columns of electrochromic windows at three different levels of transmittance: $5 \%, 30 \%$, and $60 \%$. The right view shows the window at $5 \%$. The rooms were not furnished with a task desk lamp (shown in left figure) at the time of the tests.

The blind height measurement was made with a location sensor that consisted of a potentiometer and a cord on a spool (Micro Epsilon, WDS-5000-Z200-CA-P), and the tilt measurement was made with a tilt/accelerometer sensor that detected the angle from horizontal (VTI Technologies, model SCA610CB1H1G). The blind sensors were calibrated against a visual inspection of heights and tilts. The standard deviations of the fits from the visually measured values was $\pm 5^{\circ}$ for blind tilt (range $-90^{\circ}$ to $+90^{\circ}$; with a positive value, one can see the ground from the interior), and \pm 0.1 for blind height (range 0 to 10 for blind all the way down to all the way up).

The vertical illuminances were made with a Licor illuminance sensor centered horizontally on the wall and located $122 \mathrm{~cm}$ above the floor. The luminance measurements were made by placing a Licor in a box, adjacent to the illuminance sensors, with a front opening that allowed only the surface of interest to be seen by the photosensor. The illuminance on these shielded sensors was scaled by the configuration factor of the opening to give the average luminance [6]. Both amplification and shielding of the Licor outputs introduces possible noise and error into these measurements. The raw global illuminances were therefore calibrated against values measured by a Minolta T-1 illuminance meter, while the average luminances were calibrated by measuring a grid of points in the field of view with a Minolta LS- $1101 / 3^{\circ}$ spot luminance meter under stable and relatively even lighting conditions. Simple linear fits precise to $4 \%$ were derived for the two measurements. These fits were used to convert the raw values to final illuminances and luminances. 
The work plane illuminance was determined by a photodiode sensor mounted at the level of the fluorescent lights looking down with a $60^{\circ}$ cone of view. Fluorescent power was correlated to the work plane illuminance at night and was then used to provide a measure of the fluorescent lighting levels.

In addition to physical measurements, the experiment also measured subjective responses under conditions as close to normal working conditions as we could make them. Bathroom facilities were available in a room immediately across a one-way, one-lane street from the testbed. An experimenter was present in the hallway, and was available if needed to help subjects setup any network connections that they needed on the computer. There was a phone and several pens in the test room. The hall contained a water cooler and a networked printer. Subjects doing computer work had the choice of a recent model Apple or Windows computer in the test room, or could bring their own portable computer. The Windows monitors were $43 \mathrm{~cm}$ liquid crystal display (LCD) (Samsung Syncmaster 170N) with a maximum luminance of 250 $\mathrm{cd} / \mathrm{m}^{2}$. The display used with the MacIntosh was a $43 \mathrm{~cm}$ LCD (Princeton LCD17M-BLK) with a maximum luminance of $140 \mathrm{~cd} / \mathrm{m}^{2}$. Neither monitor exhibited sharp reflections, so both were significantly superior to older cathode ray tube (CRT) type monitors in providing visibility under daylight conditions.

\section{Experimental procedure}

Subjects spent the first part of the experimental session being introduced to their surroundings and the experiment and setting up to do work. They were told that the "experiment" would consist of three sessions, so that we could test three different control algorithms with the electrochromic windows. The order of the three control algorithms was varied over the different subjects. The subjects were told that at the end of each session they would be asked to fill out a questionnaire about their impressions during the session. The questions for each session were identical, except that during the last session several questions were added about all three sessions, and a separate final questionnaire asked for comments on their overall experience, the questionnaire suitability, and the experimental procedure (see parts $\mathrm{E}$ and $\mathrm{F}$ of the questionnaire in the Appendix). Once the subjects were ready, Venetian blinds were drawn across the windows, and the subjects filled out a background and attitude questionnaire (parts A and B of the questionnaire - see Appendix). When they were finished, the blinds were raised, and the control mode on the computer was demonstrated. After the control mode was demonstrated, it was set to a default setting, and the subjects were told that they could adjust it any time during the session, but that they were to leave the blinds in the up position until we told them that it was alright to lower them (if desired) because electrochromic windows take up to several minutes to respond to changes of the control settings. They were then told that they could begin work, and the experimenter left the room. We typically allowed three minutes after starting the work session before telling subjects that they could lower the blinds. The procedure with the Venetian blinds and the instructions for the control mode were repeated at the beginning of each session. The duration of each session depended on any time constraints the subject had, the time available if more than one subject was scheduled during the day, and the time that it took subjects to fill out the questionnaires. Sessions ranged from 40 minutes to an hour, which was sufficient to allow subjects time to make judgments after actually working under the lighting, but short enough to minimize radical changes in the lighting conditions due to changing sky or sun angle conditions.

The questions in parts A and B were based on a consensus among the authors of the kinds of attributes that might affect the results. Questions about the sessions were based on questions asked by Vine et. al. [7], as modified to fit the current test situation. Both sets of questions were modified for clarity after an initial pilot run.

Three control algorithms were developed to control the windows and lighting. The automatic mode algorithm allowed the user to set an overall light level target in the room by adjusting a slider on the computer display (Figure 2). When the slider was moved, the control algorithm first changed the electric lights, and then adjusted the windows to try to maintain the same light level by harvesting as much daylight as possible. Electric light response was on the order of seconds, while full window response was on the order of three to five minutes. The automatic algorithm reduced the transmittance of the windows to $3 \%$ to block glare when there was direct sun in the plane of the window, regardless of the desire for daylight harvesting. Target light values were exceeded when daylight levels were very high.

The semi-automatic mode algorithm allowed the user to set minimum and maximum target light levels for the room. The electric lights and windows were controlled to try to maintain the light level between the user-determined minimum and maximum. The algorithm again tries to maximize daylight harvesting. In 
addition to the minimum and maximum sliders, a third slider allowed subjects to adjust the glare response by setting the desired maximum transmittance of the window when there was direct sun in the plane of the window. The default setting for the third slider was $3 \%$, which made the semi-automatic mode glare blocking identical to that of the automatic mode.

The final mode was a reference mode. The window transmittance was fixed at $60 \%$. The user was provided with a slider that adjusted only the electric light level. They were told that the computer would handle everything else. They were not told that the computer would not adjust the window. This is equivalent to a standard window with a dimmable light system. Dimming of the lights was allowed so that the user had at least one aspect of control in all three modes. The reference mode was the only mode where subjects could simply turn off the lights.
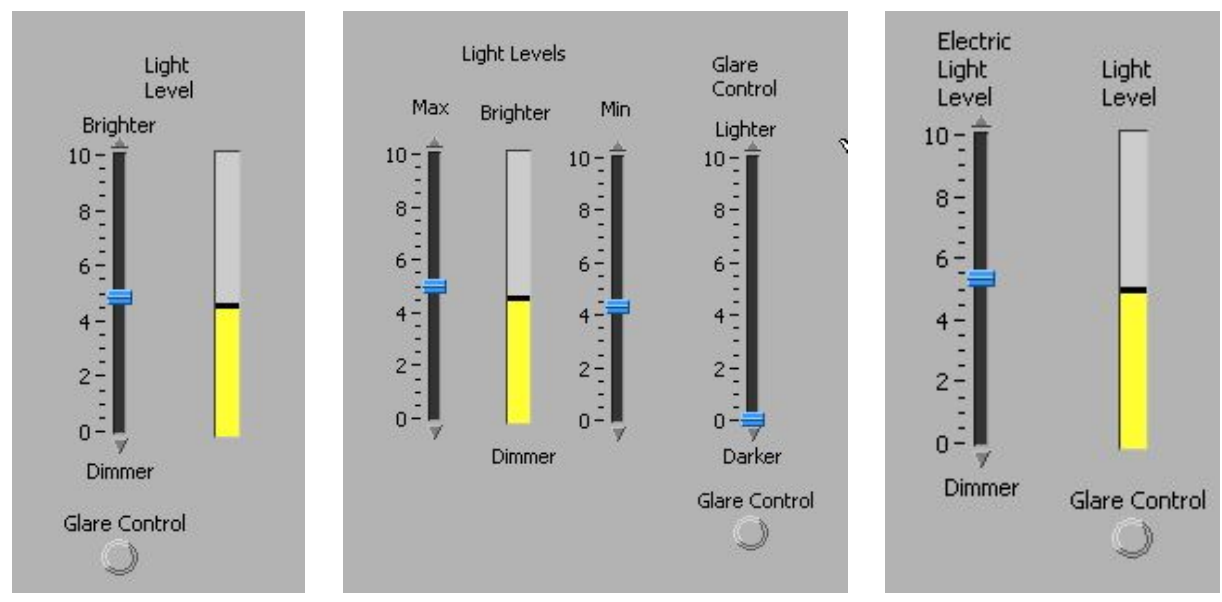

Fig. 2. User interface to the electrochromic (EC) window and lighting system: automatic mode (left), semi-automatic mode (middle), and reference mode (right). The slider switch allows users to set their preferences for interior light level and EC transmittance when in glare control mode. The "glare control" button turns green when the sun is in the plane of the window and the glare control portion of the algorithm is in effect. The unscaled bar gives the user feedback on the current overall light level.

\section{Subject selection and characteristics}

Subjects were recruited by announcements at LBNL, the University of California at Berkeley, local church, dance, or breakfast groups, personal contact with the experimenters, or personal contact via other subjects or other LBNL personnel. Most subjects were staff or University employees. Subjects were required to be 18 or over, and could not be directly associated with the research team. Because the subjects were expected to do their own work in the office, compensation was minimal. For non-laboratory staff, compensation consisted of a free lunch at the LBNL cafeteria. LBNL staff had the choice of billing two hours to a laboratory account or the free lunch.

An initial pilot test was run with eight subjects. The pilot was designed to test procedures, the questionnaires, and the lab monitoring equipment. Changes were made to the questionnaires and control modes in response to lessons learned during the pilot phase. Results from the pilot phase were not included in the results from the main study.

In the main study, forty-three subjects evaluated the operation of the electrochromic window/lighting control system in the three different modes. Subjects self reported information on their age, gender, and other characteristics which we hypothesized might affect their responses to the electrochromic windows. Color blindness, handedness and eye color were consistent with the general population and provided no other information. The remaining responses are summarized in Table 1. 
Table 1

Subject characteristics

\begin{tabular}{lrr}
\hline Characteristic & Number & Percent \\
\hline Gender & 43 & \\
Male & & $65.0 \%$ \\
$\quad$ Female & $35.0 \%$ \\
Age & 43 & \\
$\quad$ Under 40 & $39.5 \%$ \\
$\quad 40$ and up & $60.5 \%$ \\
Glasses & 43 & \\
No & & $46.5 \%$ \\
Yes & 43 & $53.5 \%$ \\
Job Classification & & $62.8 \%$ \\
Technical/Research & $16.3 \%$ \\
Management & & $16.3 \%$ \\
Other* & $4.7 \%$ \\
Clerical & 43 & \\
View of a window while working in normal work place? & & $67.4 \%$ \\
Yes & & $32.6 \%$ \\
No & 29 & \\
If yes, do you have a scenic view? & $65.5 \%$ \\
$\quad$ Yes & $34.5 \%$ \\
\hline$\quad$ No & &
\end{tabular}

* Of the 7 subjects who listed their job classification as "other," three were writers, one was an educator, one did construction work, and one was a "management/technical" person. The final subject did not list an occupation.

The subject group had a much higher proportion of technical and management personnel than for a normal office, but, as is shown later, we were unable to find any significant correlations between this variable and the subjective appraisals. Correlations between the various characteristics were examined by contingency analysis. The only statistically significant correlation among the subject characteristics (at a critical probability criterion of 5\%) was one between age and the use of glasses (likelihood ratio less than $0.2 \%$ ), as $73 \%$ of subjects 40 years and over wore glasses at work, while only $24 \%$ of subjects under 40 years did so. "Statistical" significance in this paper means that there is less than a $5 \%$ probability that a result or difference is likely to occur by chance alone.

\subsection{Attitudes}

Subjects filled out a questionnaire describing their attitudes towards building/office characteristics. The first question asked subjects to rate the importance of each of 12 items in making a pleasant and productive office environment. A summary of these results is shown in Table 2. 
Table 2

Attitudes of respondents towards importance of items in making a pleasant and productive office environment (Question B1)

\begin{tabular}{lrrrrrr}
\hline Item & Count & Mean & Std. dev. & Max & Min & Groups $^{\mathrm{b}}$ \\
\hline Good lighting & 43 & 4.4 & 0.8 & 5 & 1.5 & 1 \\
Comfortable ergonomic furniture & 43 & 4.4 & 0.8 & 5 & 1.5 & 1 \\
Good temperature control & 43 & 4.3 & 0.7 & 5 & 3.0 & 1,2 \\
Windows & 43 & 4.1 & 0.7 & 5 & 2.5 & $1,2,3$ \\
Good computer monitor & 43 & 4.1 & 0.7 & 5 & 2.3 & $1,2,3$ \\
Controllable lights or windows & 42 & 3.9 & 0.8 & 5 & 1.5 & $1,2,3$ \\
Attractive environment & 43 & 3.8 & 0.7 & 5 & 2.5 & all \\
No noise & 43 & 3.7 & 1.0 & 5 & 2.0 & $2,3,4$ \\
Privacy & 43 & 3.5 & 1.1 & 5 & 1.0 & 3,4 \\
A view & 43 & 3.3 & 1.0 & 5 & 1.5 & 4 \\
Latest computer/ operating system & 43 & 3.2 & 1.1 & 5 & 1.0 & 4 \\
Other* & 11 & 3.4 & 0.7 & 5 & 3.0 & N/A \\
\hline
\end{tabular}

a The rating scale ranged from 1 (unimportant) to 5 (very important).

b Groupings are defined in terms of statistically significant differences - see text.

* Seven of the subjects who checked "other" as a response did not specify what "other" meant. Of the remaining four subjects, two specified ventilation, one wanted a task light, and one wanted coffee or tea.

The table is organized with the most highly ranked characteristics at the top. A one-way analysis of variance (ANOVA) test showed that the differences in the ratings were statistically significant at the $10^{-14}$ probability level. The "Tukey test" for multiple comparisons [8] was used to determine which of the various means were significantly different from each other (the "other" category was not included in the analysis, as it does not constitute one particular response). The Tukey test showed that there were four overlapping groups of mean ratings, and these are shown in the last column of Table 2. Differences in the mean ratings of items that share a group are not statistically significant. For example, "no noise" is a member of groups 2, 3, and 4, while "good lighting" and "comfortable ergonomic furniture" are members of group 1 only. The mean ratings of these latter two items are therefore significantly different from the mean rating of the "no noise" item. The remaining items in Table 2 are all members of at least one of the groups 2,3 , or 4 , and are therefore have mean ratings that are not significantly different from the rating for "no noise". The list in Table 2 is probably not applicable to all other environments, as not all possible important attributes were explicitly listed. For example, in the greater San Francisco area the outdoor air quality tends to be moderately good, and no specific questions were asked about air quality as an office attribute. Even for the items that are listed, the answers should be viewed in the context of the location of the experiment. The subjects in this experiment considered good lighting as one of the most important attribute of a productive office environment. In areas with more extreme climates, temperature control might have been more important. The fact that the test site had a good view may similarly be important in interpreting the relative lack of importance of a view as compared to the mere presence of windows.

In addition to rating the importance of items to making a pleasant and productive office, subjects also rated their own sensitivity to a number of environmental factors. A summary of the sensitivity ratings is shown in Table 3. 
Table 3

Sensitivity to environmental factors (Question B2)

\begin{tabular}{lrrrrr}
\hline Item & Mean $^{\mathrm{a}}$ & Std. dev. & Max & Min & Groups $^{\mathrm{b}}$ \\
\hline Glare & 4.10 & 0.90 & 5.00 & 1.00 & 1 \\
Noise & 3.80 & 0.97 & 5.00 & 2.00 & 1,2 \\
Visual distraction & 3.60 & 0.86 & 5.00 & 2.00 & 1,2 \\
Heat & 3.30 & 1.01 & 5.00 & 1.75 & 2 \\
Gloominess & 3.30 & 0.96 & 5.00 & 2.00 & 2 \\
Cold & 3.20 & 1.06 & 5.00 & 1.50 & 2 \\
\hline
\end{tabular}

a Ratings ranged from 1 (least sensitive), through 3 (moderately sensitive), to 5 (very sensitive).

b Groupings are defined in terms of statistically signficant differences - see text following Table 2 .

An ANOVA test of the ratings showed that ratings were not the same at a probability level of $0.01 \%$. Groupings in the table were determined by a Tukey test with a 5\% criterion probability. Glare was the most significant of the factors examined.

The last question that the subjects were asked was their preferred light level. We again used a 5 point scale, with 1 = very low, $2=$ low, $3=$ moderate, $4=$ bright, and $5=$ very bright. The preferred level was $3.1 \pm 0.7$, with a range of 2 to 4.5 .

The main purposes for collecting information on the attributes and attitudes of the study population were to characterize the population, and to test for possible correlations to the appraisals of the different test modes. We also checked for relationships (correlations) among attitudes or between attributes and attitudes. Surprisingly, no relationship was found between glare and subject's judgments of the importance of windows or lighting. Significant correlations were found between the importance of quiet and sensitivity to noise $\left(\mathrm{R}^{2}=0.48\right)$, the importance of a view and the importance of windows $\left(\mathrm{R}^{2}=0.25\right)$, the importance of good lighting and the importance of light and window control $\left(\mathrm{R}^{2}=0.22\right)$, and the importance of good temperature control to the sensitivity of both heat and cold $\left(R^{2}=0.26\right)$. The $R^{2}$-values shows the fraction of the variance explained by the fit, and ranges from 1 (perfect correlation) to 0 (no correlation), or even less than 0 if the variance about the fitted values is larger than the variance around the mean. None of these results are surprising, and they therefore provide some assurance of the validity of the subject's self reporting. A result that was unexpected, although perhaps not surprising, was the markedly increased importance that subjects under age 40 ascribed to an up-to-date computer and operating system (mean value 4.0 versus 2.8 for subjects over 40 , with an $\mathrm{R}^{2}$ of 0.28 ).

The determination of the significance of the above fits allowed for the fact that there were about 20 comparisons per variable. The critical probability ( $p$-value) for 5\% significance over the set of comparisons was 0.0023 . A more focused study, with fewer comparisons, might have found more significant correlations. For example, there was a trend for women to report a higher sensitivity to cold (3.8) then men (2.9), at a significance level of 0.0077 (14\% significance over the set).

\section{Results}

\subsection{Introduction}

The test mode (automatic, semi-automatic, or reference) was the initial independent variable for judging the success of the electrochromic operation of the windows. However, it is important to have an understanding of why subjects prefer one mode or the other to be sure that it is due to the electrochromic operation itself, and not just some quirk of the test mode. The subject characteristic and attitude variables described above constituted one set of independent variables. Measured physical parameters and the type and location of the work done in the space constituted a second set of independent variables. Finally, several of what we normally considered dependent variables, such as the use of blinds, or the subject's satisfaction with control of reflections on the monitor, were included as independent variables when examining other dependent variables such as overall satisfaction or perceptions of glare. 
The type of work and location of the subjects in the test rooms are summarized in Tables 4 and 5. With regards to the type of work (Table 4), the main fraction of time was spent on the computer, although two subjects did not use a computer at all. Reading was a distant second, and all other activities were minor.

Table 4

Percentage of time spent on defined tasks (Question E2)

\begin{tabular}{lrrrr}
\hline Task & Mean & Sigma & Max & Min \\
\hline Computer & $69 \%$ & $36 \%$ & $100 \%$ & $0 \%$ \\
Reading & $21 \%$ & $30 \%$ & $98 \%$ & $0 \%$ \\
Writing (by hand) & $5 \%$ & $13 \%$ & $75 \%$ & $0 \%$ \\
Telephone & $4 \%$ & $9 \%$ & $60 \%$ & $0 \%$ \\
Other & $2 \%$ & $9 \%$ & $95 \%$ & $0 \%$ \\
\hline
\end{tabular}

* The "other" category consisted of 11 answers: 3 each of them being view and organizing, 2 of them referring to restroom breaks, and 1 each for thinking, talking, and stretching.

The majority of subject's time was spent facing the sidewall, with the window the second major direction (Table 5).

Table 5

Percentage of time facing a specified direction (Question E3)

\begin{tabular}{lrrrr}
\hline & Mean & Sigma & Max & Min \\
\hline Sidewall & $62 \%$ & $40 \%$ & $100 \%$ & $0 \%$ \\
Window & $36 \%$ & $39 \%$ & $100 \%$ & $0 \%$ \\
Door & $2 \%$ & $12 \%$ & $95 \%$ & $0 \%$ \\
Other* & $0.20 \%$ & $2 \%$ & $15 \%$ & $0 \%$ \\
\hline
\end{tabular}

* Four subjects spent some time facing "other". One was looking at the ceiling while stretching, one faced a diagonal, one faced another person while talking, and the last spent a little time walking about in the office.

The location of the work and the type of work done were related. The desktop computer faced the west wall when the subjects entered. Subjects were told that the computer could be moved if they wished. The few subjects who did move the computer moved it along the west wall. However, two subjects did not use a computer and about half the subjects brought their own lap-top computer. Overall, about $75 \%$ of the subjects using a computer faced the west sidewall, and $25 \%$ of the subjects faced the south window wall.

The above data indicated significant differences in subject's use of the rooms, and we expected that there might be some correlation of these variables to satisfaction or use of the blinds. Several weak trends were found (blind use by orientation or writing, light distribution and satisfaction of view with orientation), but none of them were statistically significant at the $5 \%$ level. 
Table 6

External conditions at time of testing

\begin{tabular}{lrrr}
\hline Factor & Mean & Min & Max \\
\hline South vertical illuminance (klux) & 33.5 & 0.8 & 97.8 \\
Horizontal Illuminance (klux) & 35.2 & 1.8 & 89.8 \\
Diffuse horizontal illuminance (klux)* & 14.8 & 1.4 & 39.3 \\
Sun Altitude $\left(^{\circ}\right)$ & 28.5 & 5.2 & 52.2 \\
Angle from south $\left({ }^{\circ},+\right.$ to west) & 19.7 & -44.8 & 71.6 \\
Profile angle (deg) ${ }^{* *}$ & 35.1 & 8.8 & 59.2 \\
Stability ratio *** & 0.77 & 0.012 & 2.74 \\
\hline
\end{tabular}

* Nominal estimates in klux.

** Profile angle $=\operatorname{atan}(\tan ($ sun altitude $) / \cos ($ sun azimuth from surface $))$. The window $(2.7 \mathrm{~m})$ or blind height divided by the tangent of the profile angle gives the depth of sunshine penetration.

*** Stability ratio (SR) was defined as $10 * \operatorname{abs}(\ln (\mathrm{E} / \mathrm{Eavg} 5)$, where $\mathrm{E}$ is the outdoor vertical illuminance measurement at time $\mathrm{t}=0 \mathrm{~min}$, and Eavg5 is the average of the five vertical illuminance measurements from $\mathrm{t}=-2$ to $+2 \mathrm{~min}$. Low values indicate a stable environment. The stability ratio was devised to give a measure of abrupt changes in outdoor light levels. See Figure 3 for examples.

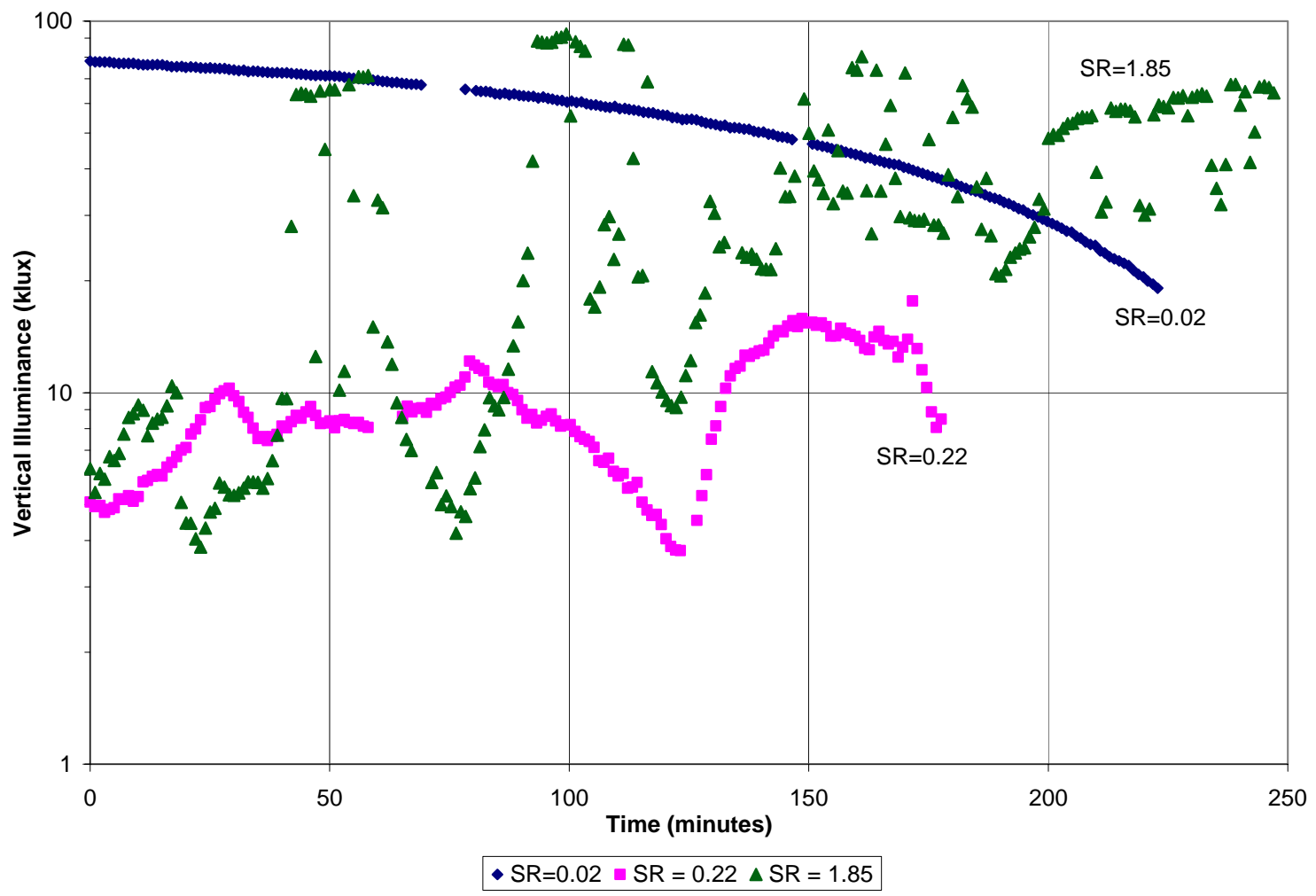

Fig. 3. Example of three days with different average stability ratios (see footnote to Table 6 for definition of SR)

Mean values of the external conditions were calculated for each session. The mean, minimum and maximum of these session means are listed in Table 6 . An analysis of variance of each of these factors against the control algorithm mode showed that there was no statistically significant difference in the external conditions over the different modes at the 5\% level.

Sky conditions ranged from heavy fog to clear skies, with about $50 \%$ of the sessions experiencing cloudy skies, and the remainder of the sessions being evenly split between partly cloudy and clear. The test period covered the months from late November to the end of March. The windows were large and faced 
south, so there was a potential for intense, direct sun penetration for a substantial number of the test sessions. Blinds were available and were used. Glare was determined by computation of the HopkinsonCornell daylight glare index (DGI) [9]. The relationship between DGI values and subjective feelings is 16 $=$ "just imperceptible", 20 = "just acceptable", $24=$ "just uncomfortable", and 28 = "just intolerable". DGI values averaged in the "just acceptable" range. Peak values of glare, generally measured just before the blinds were pulled, ranged up to "just intolerable" (see Table 7). The test room and conditions represented a fairly severe test of the ability of the electrochromic windows, and even the blinds, to control glare. We expect that the qualitative trends found in this study to have general applicability. The exact numerical values of the regressions should be treated more circumspectly, as we do not have information as to how they might vary with changes in location, window orientation or size, or time of year.

Table 7 provides an overall summary of the internal conditions that we examined as possible factors affecting user satisfaction and response. Background luminances ("West background", "Window background") are computed from a weighted difference of the illuminances on the global illuminance sensor and the shielded sensor that looks only at the surface mentioned. These two background entries give the luminances of the area surrounding the west wall and the window, respectively. The extremely high maximum for the west background occurred when there was direct sun on the unshielded east wall sensor in the period before the subject was allowed to lower the blinds.

Table 7

Internal conditions in test room

\begin{tabular}{lrrr}
\hline & Mean & Min & Max \\
\hline West wall luminance $\left(\mathrm{cd} / \mathrm{m}^{2}\right)$ & 210 & 5 & 2,421 \\
Window luminance $\left(\mathrm{cd} / \mathrm{m}^{2}\right)$ & 1213 & 22 & 9,185 \\
West wall background luminance $\left(\mathrm{cd} / \mathrm{m}^{2}\right)$ & 295 & 21 & 12,345 \\
Window wall background luminance $\left(\mathrm{cd} / \mathrm{m}^{2}\right)$ & 168 & 6 & 1,032 \\
DGI & 18.8 & $\mathrm{~N} / \mathrm{A}$ & 28.4 \\
LR: west wall/background* & 0.95 & 0.05 & 4.34 \\
LR: window/background* & 9.74 & 0.19 & 212.80 \\
\hline
\end{tabular}

* LR is the surface-to-background luminance ratio N/A: not applicable

The values in Table 7 include the periods both before and after the subjects were allowed to close the blinds. The decision to deploy blinds presumably depends upon the conditions before the blinds are deployed, while other measures may be more dependent upon the period as a whole. We therefore also accumulated "restricted" average or maximum values of the physical conditions that did not include data after blinds were drawn. The restricted values are the same as the unrestricted values if the blinds were not drawn during a session. Figure 4 shows an example of how the data were selected. 


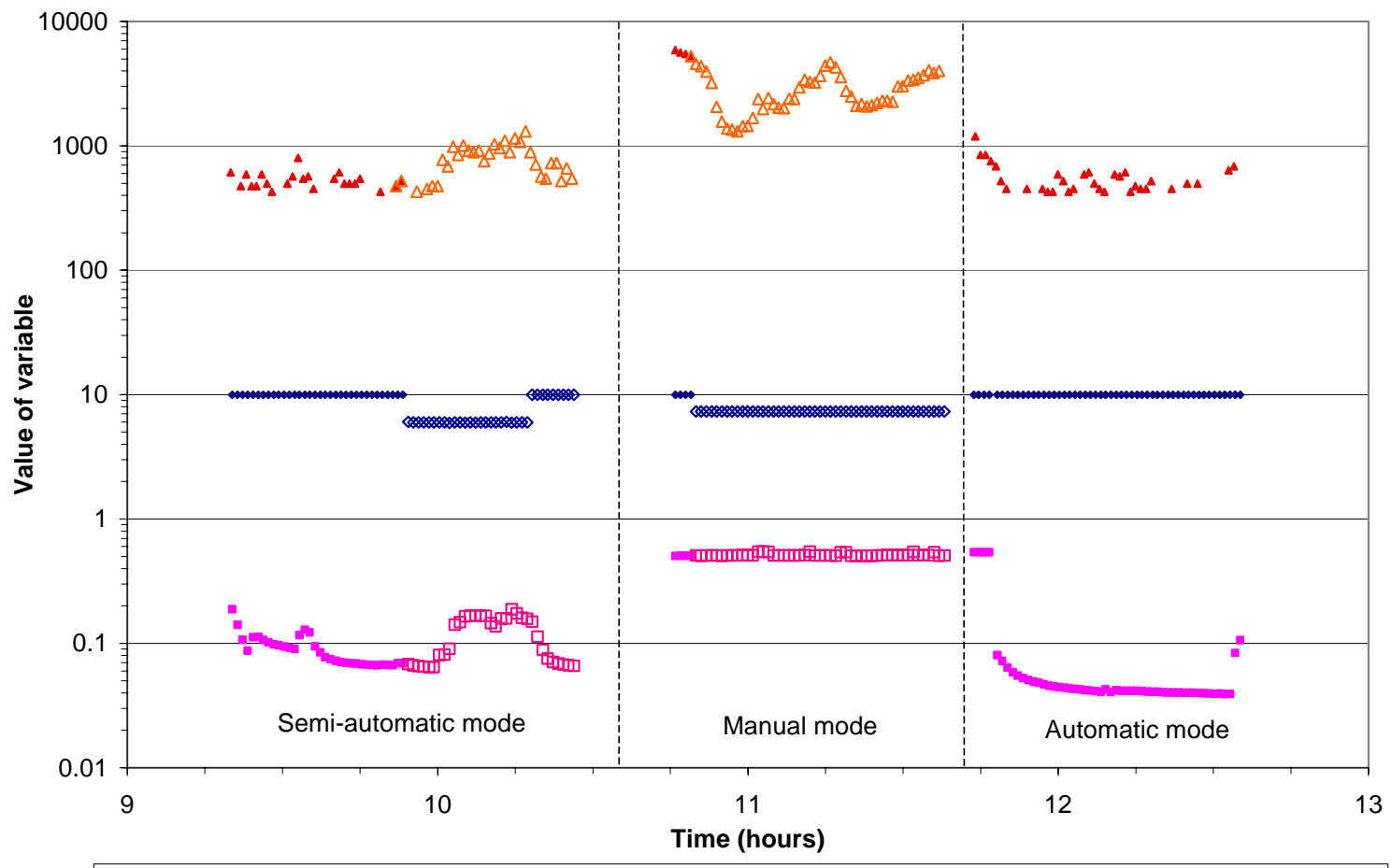

- Blind height $-\mathrm{EC}$ transmittance $\Delta$ Window luminance $\diamond$ Blind height $\square$ EC transmittance $\Delta$ Window luminance

Fig. 4. Data from a sample day showing the partitioning of the data into the "restricted" data set. Blind height was assigned a value of 10 when the blinds were fully open, and 0 when fully closed. In the automatic mode the blinds were never drawn, and all the data was included in the restricted data set (closed symbols). In the semi-automatic and reference (manual) modes only the data before the blinds are drawn are included in the restricted data sets. Values for EC transmittance range from 0 to 1 . Window luminances are in lux.

The values of many of both the unrestricted and restricted variables depend significantly upon the test mode, and they in turn, appear to strongly affect subject's use of the blinds and judgments of the performance of the test room. Table 8 lists the parameters (treated as dependent variables) that were found by a simple ANOVA (except for the " $>3000 \mathrm{~cd} / \mathrm{m}^{2}$ " parameter which was evaluated by contingency analysis) to be significant at the 0.05 probability level versus the test mode (the independent variable). Each row lists the parameter, restrictions (if any), the degree of fit in terms of $\mathrm{R}^{2}$, the significance level (probability, abbreviated "Prob.", that differences are due to chance) and the means, standard deviations, and ranges of the parameter for each mode. The parameters listed in the first half of the table were those that were found to be significant in the fitting procedure described in Section 5.3 for Table 13. The number of data points in the analysis in Table 8 range from 118 to 128, depending upon the number of points lost to data collection errors. 
Table 8

Physical parameters affected by mode

\begin{tabular}{|c|c|c|c|c|c|c|c|c|c|c|c|c|c|c|c|}
\hline \multirow[t]{2}{*}{ Parameters found in Table 13} & \multirow{2}{*}{$\begin{array}{l}\text { Restric } \\
\text {-tions* }\end{array}$} & \multirow[t]{2}{*}{$\mathrm{R}^{2}$} & \multirow[t]{2}{*}{ Prob. } & \multicolumn{4}{|c|}{ Automatic mode } & \multicolumn{4}{|c|}{ Semi-automatic mode } & \multicolumn{4}{|c|}{ Reference mode } \\
\hline & & & & avg & stdev & $\min$ & $\max$ & avg & stdev & $\min$ & $\max$ & avg & stdev & $\min$ & $\max$ \\
\hline$>3000 \mathrm{~cd} / \mathrm{m}^{2} * *$ & $\mathrm{~A}$ & 0.455 & $<.0001$ & -1 & 0.048 & -1 & -1 & -1 & 0.046 & -1 & -1 & -0.1 & 0.154 & -1 & 1 \\
\hline West wall luminance $\left(\mathrm{cd} / \mathrm{m}^{2}\right)$ & A & 0.405 & $<.0001$ & 122 & 37 & 17 & 190 & 139 & 44 & 79 & 267 & 346 & 209 & 87 & 802 \\
\hline Window luminance $\left(\mathrm{cd} / \mathrm{m}^{2}\right)$ & A, B & 0.366 & $<.0001$ & 830 & 520 & 319 & 2604 & 930 & 530 & 356 & 2523 & 2990 & 2165 & 381 & 9112 \\
\hline Tv $x$ SS-before $* * *$ & A, B & 0.353 & $<.0001$ & 3.8 & 2.3 & 0.49 & 10.1 & 4.6 & 2.9 & 0.82 & 15.00 & 19 & 16 & 0.68 & 54.2 \\
\hline Window background $\left(\mathrm{cd} / \mathrm{m}^{2}\right)$ & A & 0.327 & $<.0001$ & 90 & 39 & 33 & 184 & 103 & 49 & 45 & 331 & 245 & 160 & 9 & 707 \\
\hline Window luminance $\left(\mathrm{cd} / \mathrm{m}^{2}\right)$ & A & 0.260 & $<.0001$ & 700 & 414 & 53 & 2521 & 890 & 580 & 144 & 2547 & 1655 & 985 & 381 & 3690 \\
\hline Stability ratio & M, B & 0.053 & 0.0324 & 3.9 & 4.3 & 0.012 & 15.4 & 3.2 & 2.9 & 0.036 & 9.8 & 2.04 & 2.1 & 0.027 & 7.9 \\
\hline \multicolumn{16}{|l|}{ Parameters not found in Table 13} \\
\hline Window transmittance & A, B & 0.324 & $<.0001$ & 26 & 21 & 2.8 & 60.9 & 29 & 22 & 2.8 & 61.3 & 53.3 & 4.7 & 36.3 & 60.5 \\
\hline DGI & A, B & 0.265 & $<.0001$ & 18.3 & 2 & 14.1 & 23.6 & 18.9 & 2.3 & 14.1 & 23.4 & 21.5 & 2.7 & 15.2 & 27 \\
\hline Window luminance $\left(\mathrm{cd} / \mathrm{m}^{2}\right)$ & M, B & 0.241 & $<.0001$ & 1515 & 1425 & 405 & 8877 & 1585 & 1180 & 474 & 6165 & 3600 & 2370 & 474 & 9714 \\
\hline Window background $\left(\mathrm{cd} / \mathrm{m}^{2}\right)$ & A & 0.100 & 0.002 & 154 & 87 & 40 & 280 & 240 & 330 & 58 & 479 & 470 & 610 & 97 & 776 \\
\hline DGI & A & 0.094 & 0.0033 & 17.4 & 3 & 3.8 & 20.9 & 18.3 & 3.2 & 6.2 & 23.5 & 19.6 & 2.5 & 14.4 & 23.4 \\
\hline DGI & M, B & 0.077 & 0.0097 & 21.1 & 2.7 & 15.9 & 28.4 & 21.2 & 2.4 & 16.6 & 27.4 & 22.7 & 2.4 & 17.3 & 27.5 \\
\hline LR: west wall/background ${ }^{\wedge}$ & M, B & 0.050 & 0.0489 & 0.73 & 0.44 & 0.124 & 2.55 & 0.82 & 0.58 & 0.165 & 2.21 & 0.54 & 0.5 & 0.036 & 2.5 \\
\hline
\end{tabular}

\subsection{General results}

Dependent variables measured subject satisfaction with the window attributes (appearance, color, switching speed, and other), the relative desirability of the three operating modes, satisfaction with the light and temperature levels, light distribution and color appearance, the overall satisfaction with the windows, with and without consideration of the view, and satisfaction with environmental factors in the room (view, reflections in the monitor, light level control, window and lighting control, glare control, temperature control, and of course, other). Subjects also answered questions about the sources of glare (when present), and their reasons for using the blinds.

The bulk of our analysis was concerned with regressions against the physical parameters, however there are some general, direct results. The first, and most important, was the subject's appraisal of the relative desirability of the three window operation modes. Thirty-eight subjects ranked the relative desirability of the three window operation modes. A contingency analysis rejected the hypothesis that the three modes were equivalent at the $0.6 \%$ level. Specifically, the semi-automatic and the automatic modes, which controlled overall light levels by controlling the window transmittance and dimming the lights, were judged significantly more desirable than the reference mode (probability $<4 \%$ on binomial paired comparison tests), where the user could dim the electric lights, but the window was at a fixed $60 \%$ transmittance (Table 9).

Table 9

Desirability of window control modes (Question E12)

\begin{tabular}{lrrrr}
\hline & Semi-auto & Auto & Reference & Sum \\
\hline Most desirable mode & 18 & 15 & 5 & 38 \\
Middle & 13 & 12 & 13 & 38 \\
Least desirable mode & 7 & 11 & 20 & 38 \\
Sum & 38 & 38 & 38 & 114 \\
\hline
\end{tabular}

No obvious patterns were found between the mode preference and any subject attributes or attitudes.

In general, subjects were satisfied with the electrochromic windows, but in responding to the question about electrochromic window attributes, seven subjects used the "other" category to list specific complaints. One subject gave the windows a rating of 1 (= very dissatisfied) for lack of individual control 
over the window panes. Three subjects gave the windows an average rating of 1.9 for failing to have enough transmission range to control glare from the direct sun. One subject disliked the color differences between panes (rating $=2$ ), and two subjects thought that the window panes were too small (average rating of 2.5). Of the remaining two subjects who listed "other", one gave a rating of 4.5 to their "adjustability!", and the last gave a rating of $4.75(5=$ very satisfied) without specifying what "other" meant.

In addition to comments under "other", subjects were specifically asked whether they would have been more satisfied with electrochromics if they could darken more than they did (Question E15). A majority of the 38 subjects $(22=58 \%)$ responded affirmatively. It was further found that subjects who wear glasses were more likely to answer affirmatively $(73 \%$ versus $19 \%, \mathrm{P}=0.0025$, critical probability $=0.003)$.

Despite the fact that subjects were told that the temperature could be changed, two subjects reported being too cold in one of the sessions. Similarly, although blind use was allowed, one subject rated glare in one session as intolerable with the blinds drawn. Only one of our 43 subjects felt that the room color rendering was unnatural (Question E4). However, there was no obvious relationship between room color rendering and the mode of operation, and the average response was 3.4 on a scale of 1 to 5 , with $1=$ unnatural and $5=$ natural.

Fifty-nine percent of the subjects listed one or more glare sources during their three sessions. The most common source was the windows (59\% of total responses), but there were a significant number of responses for the wall and reflections on the computer monitor (Table 10).

Table 10

Source of glare (Question E5b)

\begin{tabular}{lrr}
\hline Source of glare & number & $\begin{array}{r}\text { Percentage } \\
\text { of responses }\end{array}$ \\
\hline Window & 56 & $59 \%$ \\
Wall surfaces & 19 & $20 \%$ \\
Reflections on the computer screen & 13 & $14 \%$ \\
Other* & 4 & $4 \%$ \\
Ceiling light & 3 & $3 \%$ \\
\hline Total responses & 95 & \\
\hline
\end{tabular}

* The "other" sources were the window mullion ( 2 cases $)$, the Venetian blinds ( 1 case) and the desk ( 1 case).

Fourteen subjects had entries in the "other" category when asked about their satisfaction with the window control system. Six responses were not identified, and 5 were related to non-window problems in the office (fan noise, and a noisy signal in one session that caused the lights to switch on and off). The remaining three "other" responses were comments that the work space was efficient or comfortable.

One of the potential advantages of electrochromic systems is that they do not block the view while they restrict the light input. The test site has a panoramic view, and we were concerned that this might have a major impact on subject's appraisals of the different window control systems. A paired comparison test was run between subject's rating of overall satisfaction with the electrochromic window control system as seen, versus how they thought they would feel if there was no view (Question E7: "Overall, how satisfied are you with the window control system in this session?", and E8: "If the window system in this session was installed in a room without a scenic view, how would you have rated it?"). Ratings on question E8 were 0.3 units lower than ratings on question E7, which was statistically significant $(\mathrm{P}<0.01 \%)$. Correlation between the questions was about $70 \%$, indicating that the responses generally responded in the same way to differences in test conditions. Since these results are based on subject's speculations about their responses, they are suggestive, but not conclusive.

A final general question asked the subjects whether they had used their blinds, and if so, asked why they had used them (Table 11). Blinds were used in about one-third of the sessions, primarily to reduce glare and/or brightness. Overheating was not an issue for most of our subjects. Although subjects were exposed to direct sun exposure, the weather during the winter and spring months of the experiment was generally mild, and the subjects were allowed to set room temperature to whatever level they preferred. 
More surprising is that only one subject identified light on their PC as an issue, yet reflections on the monitor were identified in a significant fraction of the responses as a source of glare (Table 10).

Table 11

Reasons why Venetian blinds were deployed (Questions E9a and E9b)

\begin{tabular}{lrr}
\hline & Number & $\begin{array}{r}\text { Percentage } \\
\text { of responses }\end{array}$ \\
\hline To reduce glare from daylight/ sunlight & 38 & $57 \%$ \\
To reduce overall brightness of the room & 22 & $33 \%$ \\
To reduce the heat from the sun & 3 & $4 \%$ \\
To decrease the level of visual stimulus from the outside & 3 & $4 \%$ \\
To keep light off the PC & 1 & $1 \%$ \\
\hline
\end{tabular}

\subsection{Regressions}

There were 13 variables from the questionnaires, including blind use, that were examined as dependent variables. Two of these variables, room color rendering and temperature control, were not correlated to the window/lighting control mode, nor any of the other lighting or window related parameters. Many of the "independent" variables are correlated to each other, and many dependent variables are significantly correlated to other dependent variables. Because of these correlations, there are a number of possible fits to each variable. To compensate for the effect of multiple fits we used a critical (maximum) probability of 0.001, for the fit as a whole, to judge significance (see discussion in Section 4.1). Parameters were included in the fits at the 0.05 level so as not to exclude reasonable correlations.

Our first interest was in fits that included the mode variable, as this relates most directly to questions concerning the relative desirability of the electrochromic windows versus a static window. The automatic and semi-automatic modes both represent possible electrochromic window operation modes, while the reference mode maintained the electrochromic window at a fixed transmittance of about $60 \%$, thus making it equivalent to a standard window.

The fits listed in Table 12 are based on step-wise multi-variate regressions with mode and subject being the first variables entered, with other variables being entered sequentially after these two. Table 12 only lists those fits where mode was statistically significant (probability $<0.05$ ). Other variables were rejected from the fits in Table 12 if their inclusion made the mode variable not significant.

The use of subject as a categorical variable in these fits is equivalent to a within subject analysis, however subject was rejected as a significant source of variance for blind use, and for the rating of the light level. These two analyses are not within subject analyses, and are less powerful in "explaining" the variance in the original data $\left(\mathrm{R}^{2}<0.3\right.$ versus $\mathrm{R}^{2}>0.5$ for the remaining fits). The fits listed in Table 12 are not the "best" or most explanatory fits, so only the mean values versus mode (columns $3-5$ ), the estimated statistical significance of the mode parameter (column 6), and the value of $\mathrm{R}^{2}$ (column 7) are listed, along with the question \# (column 1) and short description of the question (column 2). Trends for variables not listed in the table were not statistically significant, but were consistent with the trends in the table. The message in Table 12 is that the operable modes of the electrochromic window consistently provided higher satisfaction than a fixed transmittance mode, and also resulted in significantly less use of the blinds.

The mode can influence the subjective response indirectly through its influence on the physical attributes of the space, or directly because of experimenter bias, subject cueing, or an increase in the sense of control or empowerment due to the different control algorithms. The regressions in Tables 13a-13c were done in stepwise manner, with parameters being withdrawn from the fit if the inclusion of a later parameter renders them not significant. The "mode" parameter did not retain statistical significance for any of the dependent variables once the physical parameters were included, and is therefore not included in these fits. This is consistent with the hypothesis that it is the effect of mode on the physical parameters that determined the responses. 
Table 12

Mode-based fits

\begin{tabular}{|c|c|c|c|c|c|c|}
\hline $\mathrm{Q} \#$ & Question & Auto & Semi & Ref. & Probability & $\mathrm{R}^{2}$ \\
\hline$\overline{\text { E9a }}$ & Venetian blinds not used $(\%=$ not used $)$ & $79 \%$ & $77 \%$ & $38 \%$ & 0.0001 & 0.26 \\
\hline E7 & Overall satisfaction with window control system & 3.81 & 4.05 & 3.51 & 0.0046 & 0.56 \\
\hline $\mathrm{E} 4 \mathrm{~b}$ & Rating for lighting level of test room ( $1=$ too dim, $5=$ too bright $)$ & 3.08 & 3.25 & 3.46 & 0.0053 & 0.17 \\
\hline E6 & Satisfaction with following attribute of EC window control system: & & & & & \\
\hline E6b & Glare control & 3.77 & 3.71 & 3.22 & 0.0069 & 0.55 \\
\hline E6c & Control of reflections on computer monitor & 4.17 & 4.05 & 3.73 & 0.0074 & 0.66 \\
\hline E6f & Ability to control windows/ lighting & 3.72 & 3.97 & 3.41 & 0.0120 & 0.55 \\
\hline
\end{tabular}

Unless otherwise listed, larger values represent higher satisfaction $(1=$ very dissatisfied, $5=$ very satisfied $)$

Table 13a shows the degree of fit that was attained using subject and the physical parameters described in Table 8 as the independent parameters. Switching from fits against mode to fits against physical parameters increases the explanatory power (column $3: \mathrm{R}^{2}$ ) of the six variables that had statistically significant fits against mode, and increased the total number of significant fits from 6 to 11 . Blind use was fit as a nominal (yes/no) logistic fit (probability of response $=1 /\left(1+\mathrm{e}^{-\mathrm{XB}}\right)$, where $\mathrm{X}$ is the set of independent parameters, and the B are the fitted coefficients), and the test statistic (column 4) is the chisquare value of the fit [10]. The remaining variables were fit as multivariate regressions and the test statistic is the F statistic. The number of data points (column 5) varies both because of occasional dropped values for the physical parameters, and occasional non-answers by the subjects. All but the fit for the use of blinds include subject as a categorical independent variable and therefore have on the order of 40 fit parameters (column 6). Subject was not a statistically significant variable in the blind fit, and the fit has only 3 parameters plus a constant. The last column shows that all of the fits are significant at below the criterion probability level of 0.001 .

Table 13a

Physical parameter based fits: degree of fit

\begin{tabular}{lrrrrr}
\hline Dependent variable & $\mathrm{R}^{2}$ & $\begin{array}{r}\text { Value of } \\
\text { statistic }\end{array}$ & $\begin{array}{r}\text { No. of } \\
\text { data points }\end{array}$ & $\begin{array}{r}\text { No. of fit } \\
\text { parameters }\end{array}$ & $\begin{array}{r}\text { Significance } \\
\text { level }\end{array}$ \\
\hline E7) Overall Satisfaction & 0.622 & 3.06 & 124 & 43 & $<.0001$ \\
E8) Satisfaction without view & 0.725 & 4.66 & 120 & 43 & $<.0001$ \\
E9a) Use of Blinds & 0.642 & 102 & 124 & 3 & $<.0001$ \\
E6a) Light level control & 0.685 & 3.93 & 119 & 42 & $<.0001$ \\
E6b) Glare control & 0.566 & 2.39 & 123 & 43 & 0.0004 \\
E6c) Reflection on monitor & 0.717 & 4.49 & 112 & 40 & $<.0001$ \\
E6f) Control of windows/lighting & 0.632 & 3.27 & 123 & 42 & $<.0001$ \\
E4b) Light level satisfaction & 0.569 & 2.42 & 120 & 42 & 0.0004 \\
E4c) Light distribution satisfaction & 0.598 & 2.76 & 124 & 43 & $<.0001$ \\
E5a) Glare Sensation rating & 0.645 & 3.29 & 122 & 43 & $<.0001$ \\
E6c) View & 0.643 & 3.26 & 122 & 43 & $<.0001$ \\
\hline
\end{tabular}

Table 13b lists the independent parameters for the fits in Table 13a, along with their values and their significance levels. The independent parameters (column 3 ) are identified by numbered notes at the bottom of the table. Column 4 lists the value of the parameter, except when the parameter is listed as Subject\#. For subject as an effect the value of interest is the variation between subjects, and the value listed in column 4 is accordingly the root-mean-square average of the subject effects. These values are listed in italics. The values of the parameters usually do not provide information as to their relative importance, as they are affected by the mean and range of the input data values. Column 5 lists scaled estimates of the 
parameters. The scaled estimates are computed by subtracting the mean from the input data value, and dividing by product of 0.5 times the range. This does not affect the estimates for categorical variables, as these are already scaled to a range of $2(-1$ to +1$)$. The scaled estimates provide an indication of the relative importance of the different parameters in a fit over the range of the data. The last (sixth) column lists the significance level of the parameter in the fit. Parameter significance levels below 0.001 exceed the critical probability for the fit as whole are firm correlations, and are marked in bold.

The regressions in Table $13 \mathrm{~b}$ are linear regressions. For example, overall satisfaction (y) is simply:

$$
\mathrm{y}=3.934-0.953 * \mathrm{P}_{1} \pm 0.625
$$

where $P_{1}$ is the $>3000 \mathrm{~cd} / \mathrm{m}^{2}$ variable, and the value 0.625 is the RMS average of the subject effects. If the window luminance is above $3000 \mathrm{~cd} / \mathrm{m}^{2}$ then $P_{1}=1$, and if it is less than $3000 \mathrm{~cd} / \mathrm{m}^{2}$ then $P_{1}=-1$. All the dependent parameters, except for the logarithm of the blinds odd ratio, are restricted to the range of 1 to 5 , but the predicted values may exceed this range, especially if one includes subject variation. In our example, if $P_{1}=-1$, and the subject variation is greater than 0.11 then the predicted value exceeds 5 .

There are 10 independent parameters listed in Table 13b, but it is less complex than this seems, as several of them are related to each other, and the others are specific to one or another dependent parameter. Window luminance, in four guises, is a factor in eight of the fits. The average over the entire session is a parameter for the glare control response. The average of the same window luminance, but excluding the period after the blinds are drawn, is a parameter for two dependent parameters, while a transform of this later average to a categorical variable $\left(>3000 \mathrm{~cd} / \mathrm{m}^{2}\right)$, which is indicative of a non-linear response, is a parameter for four variables. Thus all three of these parameters are based on the same physical measurement. The parameter TvxSS (window transmissivity times exterior vertical illuminance) is also a measure of the window luminance, but is an average over a wider view angle than the direct measure of window luminance. We hypothesized that it would therefore more indicative of how well the window is controlling the entry of light. It was a parameter for people's satisfaction with the ability to control the windows and lighting. The spatial distribution of luminance is a factor in glare and transient adaptation. The window background luminance correlated to judgments of the severity of reflections on the monitor, and it and the window luminance to background ratio were the parameters for light level control. Although window luminances were higher than other luminances in the room, most subjects faced west for most of their time in the room. The west wall luminance, and the west wall luminance ratio were the most significant parameters for the judgment of light level satisfaction. The last two parameters, vertical illuminance over 20 klux, and the stability ratio, are explicitly measures of the outside conditions, and were parameters only for the frequency of blind use.

Some of the variables in Table 13b are marked as not being included in an alternate or best fit. This is because many of the parameters are related to each other, which means that there are a number of possible fits. Inclusion in Table 13b does not establish causality, and it is possible that more research would show that better fits could be obtained with different variables. Table 13c lists parameters for a number of possible alternate fits. Column 2 lists parameters that might contribute, but cannot be fit with the data collected. This includes background and attitude parameters, such as age, gender, importance of windows or lighting, and so on, as they have only one value per subject, and therefore cannot be included in a fit with the subject variable. For this reason, fits were always done with, and without, the subject variable. If the best fit included the subject variable, but the fits without it included a background or attitude variable or variables, then these later variables are listed in the tables as possible contributing variables.

The third column of Table 13c lists variables that gave fits that were nearly as good as the fits in Table 13b. The variables listed in this column replace the variables marked with an asterisk in Table 13b. The parameters in this column include some variables, such as reflections in the monitor, that are subjective variables. Some of these variables are treated as dependent variables in other fits. The fourth column lists cases where these subjective variables actually lead to better fits than the physical parameter based fits in Tables 13a and 13b. Their inclusion in these two columns suggests that they may indicate the mechanism by which a physical variable affects the subjective variable that is being fit. The last column in Table 13c gives the degree of fit $\left(\mathrm{R}^{2}\right)$ that corresponds to the different parameters. If several parameters are part of the same fit there is only one value of the $\mathrm{R}^{2}$. Fits against contributing variables have much lower $\mathrm{R}^{2}$ than the other fits, as subject is not a variable in these fits. 
Table 13b

Physical parameter based fits: parameter values

\begin{tabular}{|c|c|c|c|c|}
\hline Dependent variable & Independent variable & Value & Normalized & $\begin{array}{r}\text { Significance } \\
\text { level }\end{array}$ \\
\hline \multicolumn{5}{|c|}{ E7) Overall Satisfaction } \\
\hline & Intercept & 3.93442 & 3.934 & $<.0001$ \\
\hline & Subject \# & 0.62461 & 0.625 & 0.000 \\
\hline & n1) $>3,000 \mathrm{~cd} / \mathrm{m}^{2}$ & -0.95333 & -0.953 & $<.0001$ \\
\hline \multicolumn{5}{|c|}{ E8) Satisfaction without view } \\
\hline & Intercept & 3.67093 & 3.671 & $<.0001$ \\
\hline & Subject \# & 0.80076 & 0.801 & $<.0001$ \\
\hline & $\mathrm{n} 1)>3,000 \mathrm{~cd} / \mathrm{m}^{2}$ & -1.00000 & -1.000 & $<.0001$ \\
\hline \multicolumn{5}{|l|}{ E9a) Use of Blinds } \\
\hline & Intercept $*$ & 3.71196 & 1.463 & 0.0006 \\
\hline & n2) Average luminance (before) & -0.00215 & -9.452 & 0.0006 \\
\hline & n3) Max stability (before) & 0.85061 & 6.562 & 0.0003 \\
\hline & n4) $>20$ klux $*$ & -2.82080 & -1.410 & 0.0017 \\
\hline \multicolumn{5}{|c|}{ E6a) Light level control } \\
\hline & Intercept & 3.70191 & 3.715 & $<.0001$ \\
\hline & Subject \# & 0.80957 & 0.810 & $<.0001$ \\
\hline & n5) Window background $\mathrm{cd} / \mathrm{m}^{2}$ & -0.00282 & -0.983 & $<.0001$ \\
\hline & n6) Window luminance ratio & 0.04301 & 1.027 & 0.0024 \\
\hline \multicolumn{5}{|l|}{ E6b) Glare control } \\
\hline & Intercept & 4.06096 & 3.557 & $<.0001$ \\
\hline & Subject \# & 0.71649 & 0.716 & 0.0024 \\
\hline & n7) Window luminance & -0.00047 & -0.851 & $<.0001$ \\
\hline \multicolumn{5}{|c|}{ E6c) Reflection on monitor } \\
\hline & Intercept & 4.31862 & 3.931 & $<.0001$ \\
\hline & Subject \# & 0.70495 & 0.705 & $<.0001$ \\
\hline & Window background $\mathrm{cd} / \mathrm{m}^{2} *$ & -0.00264 & -0.921 & $<.0001$ \\
\hline \multicolumn{5}{|c|}{ E6f) Control of windows/lighting } \\
\hline & Intercept & 4.03760 & 3.687 & $<.0001$ \\
\hline & Subject \# & 0.79387 & 0.794 & $<.0001$ \\
\hline & Tv*SS-avg-before & -0.03944 & -1.060 & $<.0001$ \\
\hline \multicolumn{5}{|c|}{ E4b) Light level satisfaction } \\
\hline & Intercept & 2.91541 & 3.252 & $<.0001$ \\
\hline & Subject \# & 0.38029 & 0.380 & 0.0013 \\
\hline & West luminance ratio (before) & 0.47458 & 0.546 & 0.0074 \\
\hline & West luminance & 0.00091 & 0.355 & 0.0016 \\
\hline \multicolumn{5}{|c|}{ E4c) Light distribution satisfaction } \\
\hline & Intercept & 3.41969 & 3.420 & $<.0001$ \\
\hline & Subject \# & 0.64470 & 0.645 & 0.0003 \\
\hline & $\mathrm{n} 1)>3,000 \mathrm{~cd} / \mathrm{m}^{2 *}$ & -0.55333 & -0.553 & 0.0055 \\
\hline \multicolumn{5}{|c|}{ E5a) Glare Sensation rating } \\
\hline & Intercept & 2.34674 & 2.347 & $<.0001$ \\
\hline & Subject \# & 0.78180 & 0.782 & $<.0001$ \\
\hline & $\mathrm{n} 1)>3,000 \mathrm{~cd} / \mathrm{m}^{2 * *}$ & 0.59333 & 0.593 & 0.0075 \\
\hline \multicolumn{5}{|l|}{ E6e) View } \\
\hline & Intercept & 4.44846 & 4.265 & $<.0001$ \\
\hline & Subject \# & 0.57729 & 0.577 & $<.0001$ \\
\hline & n2) Average luminance (before) & -0.00012 & -0.520 & 0.0018 \\
\hline
\end{tabular}


Notes to Table 13b:

Bold Parameter significance levels below 0.001 exceed the critical probability for the fit as whole are firm correlations, and are marked in bold.

Italics Indicates root-mean-square average of the subject effects.

* Variable not included in alternate fit - see Table 13c.

** Variable not included in best fit - see Table 13c.

$+\quad \log$ (base e) odds ratio of no to yes

$++\quad$ When the parameter is subject \#, the value is the RMS average of the subject effects.

n1) $\quad>3000 \mathrm{~cd} / \mathrm{m}^{2}$ : This is a computed from the "Luminance-average-before" variable (see $\mathrm{n} 2$ below) with values $-1\left(\leq 3000 \mathrm{~cd} / \mathrm{m}^{2}\right)$ or $1\left(>3000 \mathrm{~cd} / \mathrm{m}^{2}\right)$.

n2) Luminance-average-before: The average luminance of the window, excluding any data taken after the blinds are pulled. This is the test variable for the $>3000 \mathrm{~cd} / \mathrm{m}^{2}$ parameter. See Section 5.1.

n3) Max stability before: The maximum value for the stability ratio excluding any data after the blinds are drawn.

n4) $>20$ klux: This is computed from the south outdoor vertical illuminance and has the values $-1(\leq 20 \mathrm{klux})$ or +1 ( $>20$ klux).

n5) Window background luminance $\left(\mathrm{cd} / \mathrm{m}^{2}\right)$ : The average luminance of the background to the window. This is computed by subtracting the illuminance from the window as measured by the shielded sensor on the rear wall from the illuminance on the unshielded sensor and dividing the difference by the configuration factor for the background area.

n6) Window luminance ratio: The ratio of the window luminance to the window background luminance (see above).

n7) Window luminance: The average luminance of the window as viewed from the rear of the room.

n8) Tv*SS-avg-before: The average of the product of the window transmittance and the south outdoor vertical illuminance on the window wall excluding data taken after the blinds are drawn. The vertical illuminance sensor sees light from the entire southern hemisphere view, so this value is not the same as the average window luminance (n2), because the latter is based on the restricted view through the window from the back of the room.

n9) West luminance ratio (before): The luminance ratio between the west wall and the background (excluding any data after blinds are pulled)

n10) West wall luminance: The average luminance of the west wall as viewed from the east wall. 
Table 13c

Alternate fit parameters

\begin{tabular}{|c|c|c|c|c|}
\hline Dependent variable & Contributing & Alternate & Best fit & $\mathrm{R}^{2}$ \\
\hline E7) Overall satisfaction & & & E6c) Monitor reflections & 0.783 \\
\hline E8) Satisfaction & & & E6c) Monitor reflections & 0.770 \\
\hline without view & & & E6c) View & \\
\hline \multirow[t]{3}{*}{ E9a) Use of blinds } & & B1) Controllable & & 0.628 \\
\hline & & lights or windows & & \\
\hline & & $\begin{array}{l}\text { B2a) Sensitivity to } \\
\text { glare }\end{array}$ & & \\
\hline \multicolumn{5}{|l|}{ E6a) Light level control } \\
\hline E6b) Glare control & & & E6c) Monitor reflections & 0.758 \\
\hline E6b) Glare control & B1K) Good monitor & & & 0.500 \\
\hline E6c) Reflection on & & n2) Average & & 0.700 \\
\hline monitor & & luminance (before) & & \\
\hline $\begin{array}{l}\text { E6c) Reflection on } \\
\text { monitor }\end{array}$ & & E9a) blind use & & 0.711 \\
\hline $\begin{array}{l}\text { E6c) Reflection on } \\
\text { monitor }\end{array}$ & & n1) $>3000 \mathrm{~cd} / \mathrm{m}^{2}$ & & 0.699 \\
\hline $\begin{array}{l}\text { E6f) Control of } \\
\text { windows/lighting }\end{array}$ & $\begin{array}{l}\text { B1c) Window } \\
\text { importance }\end{array}$ & & & 0.134 \\
\hline \multicolumn{5}{|l|}{$\begin{array}{l}\text { E4b) Light level } \\
\text { satisfaction }\end{array}$} \\
\hline $\begin{array}{l}\text { E4c) Light distribution } \\
\text { satisfaction }\end{array}$ & $\begin{array}{l}\text { B1K) Good monitor } \\
\text { B2a) Glare sensitivity } \\
\text { A3) Age }\end{array}$ & & & 0.238 \\
\hline $\begin{array}{l}\text { E4c) Light distribution } \\
\text { satisfaction }\end{array}$ & & $\begin{array}{l}\text { E6c) Monitor } \\
\text { reflections }\end{array}$ & & 0.618 \\
\hline E5a) Glare sensation rating & & & E6c) Monitor reflections & 0.678 \\
\hline E6c) View & $\begin{array}{l}\text { B1) Controllable lights } \\
\text { or windows }\end{array}$ & & & 0.095 \\
\hline
\end{tabular}

Ten of the eleven dependent variables in Tables 13a-13c are subjective ratings. A Principal Component Analysis (PCA) was run to determine how much information would be lost if these dependent variables were combined into a smaller set of variables.[10] The PCA indicated that two linear combinations (vectors) of the ten subjective ratings captured $62 \%$ of the variance. The addition of further vectors only slowly increased the explanatory power of the PCA, and it took 8 vectors to exceed 95\% variance. This indicates that the dependent set is not highly redundant.

The first vector in the PCA explained $49 \%$ of the variance, but is hard to characterize as due to a particular significant factor. Rotation for simplification, followed by scaling so that the maximum coefficient is one, left only 3 dependent variables with coefficients less than 0.5 , indicating that the factor is almost a simple average of all the ratings except light level, light distribution, and glare sensation. The second rotated PCA vector (13\% of the variance), has only 4 components above 0.5 : glare sensation and control, light level, and reflections in the monitor. This suggests that glare acts as a weakly unifying factor in the set of dependent variables that were studied. 


\subsection{Other results}

In addition to looking at subjective response and blind usage, we also kept a record of blind height and tilt, the user control settings, and fluorescent light use in the room. In the automatic and semi-automatic modes, the user controlled the overall light level, while in the reference system, the user set the fluorescent light level. Although users preferred the automatic and semi-automatic systems, they actually used more light (and energy) with them (Table 14).

Table 14

Average fluorescent illuminance (lux) by mode

\begin{tabular}{rrr}
\hline Automatic & Semi-automatic & Reference \\
\hline 270 & 193 & 165 \\
\hline
\end{tabular}

Figure 5 shows that this surprising result was due in part to the large number (30\%) of subjects who turned the lights off in the reference mode. The minimum overall light level setting in the semi-automatic and automatic modes was 200 lux, but most users preferred more than this, and only about $10 \%$ set the control settings to the minimum. The average setting for the automatic mode was 490 lux, while for the semi-automatic mode the minimum and maximum settings (see Section 3) were 415 and 570 lux, respectively. Fifty percent of the subjects left the glare mode setting in the semi-automatic mode at the default setting of 3\% transmittance. One subject turned the glare setting to $60 \%$ transmittance (effectively rendering the glare mode inactive). The average setting was $11 \%$ transmittance in the presence of direct sun.

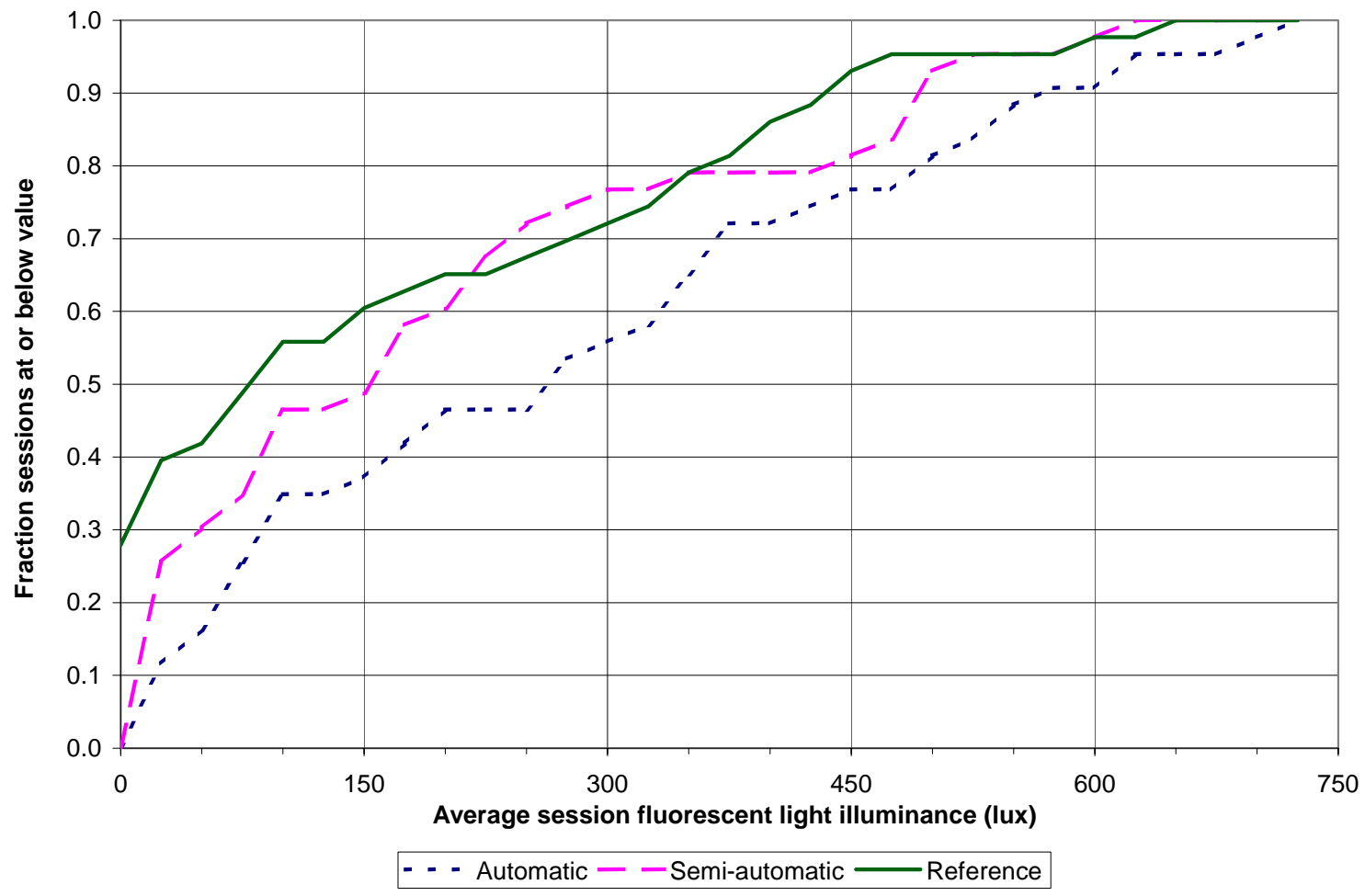

Fig. 5. Cumulative frequency distribution showing the increased fraction of subjects who turned the lights fully off in the reference mode as compared to the other modes. 
The physical cause for the relationship between mode and fluorescent illuminance (Ef) is due to the effect of mode on the window luminance and operation. This can be seen from the best fit equation $\left(\mathrm{R}^{2}=\right.$ $0.70)$ :

$$
\text { Ef }(\text { lux })=1040-\mathrm{P}_{1} *\left(99 * \mathrm{P}_{1}+629\right)-55 * \mathrm{P}_{2}, \pm 113 \text { (subject variability) }
$$

where $P_{1}$ is the window luminance ratio before the blinds were pulled, and $P_{2}$ is a blinds variable which is 1 when the blinds are pulled, and -1 when they are up. Table 11 showed that blind use was correlated to mode in agreement with this fit. The window luminance ratio also showed a trend with mode that was consistent with this equation, but it was not statistically significant. These results are covered more fully in the discussion.

Although the blinds were used more often in the reference mode than the other modes, there appeared to be no significant difference in the way that they were used once deployed. The tilt averaged $70^{\circ} \pm 15^{\circ}$ (view toward ground from interior). Blind height was more variable, averaging $5.5 \pm 3.5$.

\section{Summary and discussion}

The electrochromic windows were found to be able to provide a satisfactory work environment. Table 12 shows that subjects generally rated the two operable electrochromic modes as satisfactory for most questions. They also rated the glare as barely above perceptible for these two modes.

The results in Tables 9 and 12 further show that subjects prefer the two operating electrochromic window conditions over the non-operating condition. The results in Tables 8 and 13a-13c indicate that these preferences were related to perceived reductions in glare, as well as measurable reductions in window luminances. This combination of results is consistent with the hypothesis that the electrochromic windows can provide a significant improvement in the office environment. They are inconsistent with the alternate hypotheses that there are no improvements, or that any improvements are merely due to judgments about the control algorithms.

A Principal Component Analysis identified glare as a week unifying factor for the dependent variable set. The strongest factor was an average of many variables, and could not be identified in terms of one particular type of response.

Our subject group was not typical of the normal office workforce in terms of their job status or background, however, we were unable to find any significant correlations between subject attributes and our dependent variables. Our subjects did their normal office work in our test room, and the test rooms were, with the exception of some monitoring equipment on the windows and walls, set up as normal offices. It is possible that some of our results, such as the relatively high importance our subjects assign to lighting, or the high importance of monitors and relatively low importance of having the latest computer and operating system, are artifacts of our sample selection that we cannot evaluate within our sample. However, the evaluations of the window operation are strongly correlated to physical differences in the room, and we therefore believe that these results are valid, and should apply to a normal workforce.

The vast majority of our subjects did at least some computer work. Although we did not find any statistically significant correlation of our subject response relative to the work they were doing, the preponderance of computer work means that statistical sensitivity to variations in work type was relatively poor. One should note in particular the importance of reflections on the computer monitor in regressions against appraisals of satisfaction and glare. Our results should apply where computer use is common, and we caution the reader that they may not apply where computers are not used.

All the monitors in our experiment used flat LCD-type displays. Reflections in the flat panel displays were not sharp, and were hard to distinguish as images unless the reflecting object was extremely close. During the pilot phase of the study, regular CRT displays were used for the first few subjects. The CRT displays were less bright, and showed sharp well-defined reflected images. Direct sun reflections off the CRT displays made them totally unreadable. Our observations suggest that the use of high-quality LCD displays is a critical factor in user satisfaction in any office with high window luminances and the possibility of direct sun penetration, as reflections off the monitor were a problem even though we used LCD monitors. It is likely that our results favoring electrochromic windows would have been even stronger if we had used lower quality CRT or flat panel displays. 
Our data supported the hypothesis that a dimmable window could reduce blind use. There were three parameters that were strongly correlated to blind use. Two of the parameters were related to the outside conditions, the maximum stability ratio and the outdoor vertical illuminance, and were therefore independent of the window operation, while the third, window luminance, was strongly influenced by the ability of the window to dim.

Our results for fluorescent light and energy use were less satisfactory. The direct correlations suggest that electrochromic operation increased fluorescent light use. Part of this result may be due to the control algorithms we used. The reference control system directly controlled the electric lights, and allowed the subjects to turn them off. A substantial fraction of our subjects did just that. The electrochromic systems were designed with daylight harvesting in mind, and controlled the overall light level. Control of the electric lights was thus somewhat indirect, and it was not possible to simply turn them off. One subject commented very unfavorably on this, noting that even with a regular electric switch she could at least turn off her lights. However, directly turning off the lights may not be as suitable for an open plan space as it was for our testbed, which is equivalent to a private office. Thus our finding may not fully generalize to an open-plan space.

Turning lights fully off is not behavior that we had expected from a significant fraction of our sample, and we want to note again that our sample pool was not typical of the normal work population. It is possible that subjects were more aware of the lighting or energy conservation than a normal population, so that the surprising results with the fluorescent lighting may be anomalous, and should be confirmed in a separate study.

Having noted the above, we want to emphasize that a fraction of the increase in lighting used with electrochromic operation is probably due to the electrochromic window itself. The amount of daylight available in the two electrochromic modes is less than for the reference non-electrochromic mode, and so it stands to reason that there might be some increase in the electric lighting with the electrochromic mode. Blinds do not block all the daylight, especially when they are not fully tilted or deployed, and they reflect some room light back into the room. The average luminance of the window system for no blinds versus full blinds was typically only about $6: 1$, while the transmittance of the electrochromic windows could be varied over a range of about 20:1. In short, the reference mode tended to have more light available from the window, even though the blinds were pulled more often, than the two control modes. Increased fluorescent light use is clearly a potential problem, and should be examined further. One possibility that we believe is particularly promising is to control the upper windows differently from the lower ones, so as to allow daylight in the upper portion while blocking glare through the lower view portion of the window.

The data we collected has also provided insights in questions that were not explicitly part of the original research design. Various measures of window luminance were the main explanatory variables for 10 of the 11 fits shown in Tables 13a and 13b. One interesting and perhaps useful insight is the decidedly non-linear response to the window luminance conditions in some of the fits. Figure 6 shows the probability that the subject pulled the blinds as a function of the outdoor vertical illuminance on the window. Few subjects use the blinds when there is less than $20 \mathrm{klux}$, and blind use fits better to a binary $(0,1)$ variable at 20 klux, than it does to a log-linear logistic.

Figure 7 shows the blind probabilities against the window luminance before the blinds were pulled. The blind fit follows an exponential logistic form of the window luminances. Only one subject failed to pull the blinds when the luminance reached $3000 \mathrm{~cd} / \mathrm{m}^{2}$. For 4 out of 5 of the other cases where this variable was significant (Table 13b), a binary variable at $3000 \mathrm{~cd} / \mathrm{m}^{2}$ led to better fits than a linear fit to the original variable. A binary "go, no/go" response is potentially very useful for design purposes because of its extreme simplicity, however, it should be noted that the criterion or threshold value that we found may only be appropriate for the orientation, size, and location of the windows that we tested. A wider range of test conditions would need to be analyzed to see if the criterion values are reproducible, and whether they are stable over the different conditions or at least vary in a predictable way. 


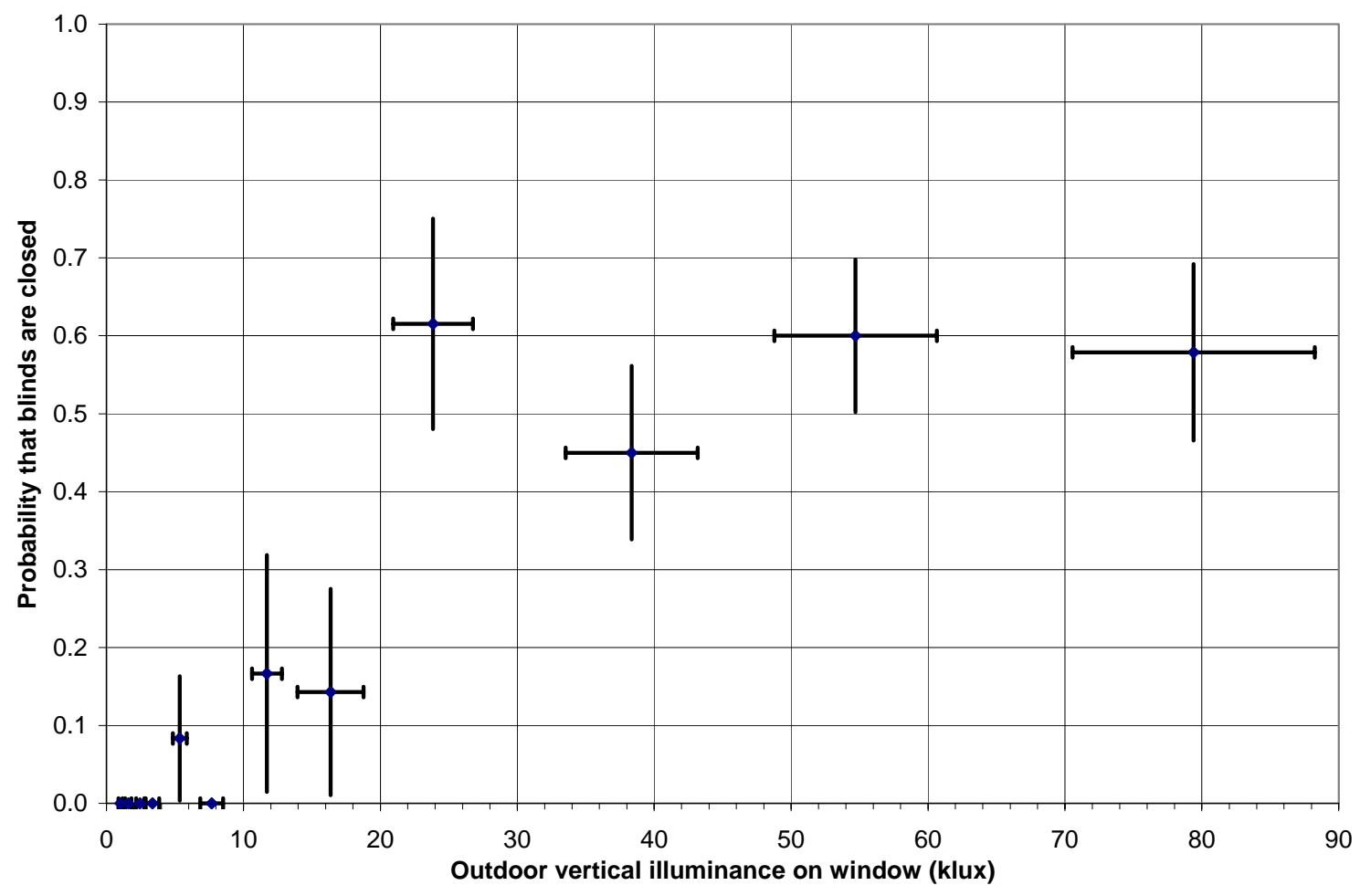

Fig. 6. Probability of pulling blinds versus outdoor vertical illuminance on window (mean and standard deviation)

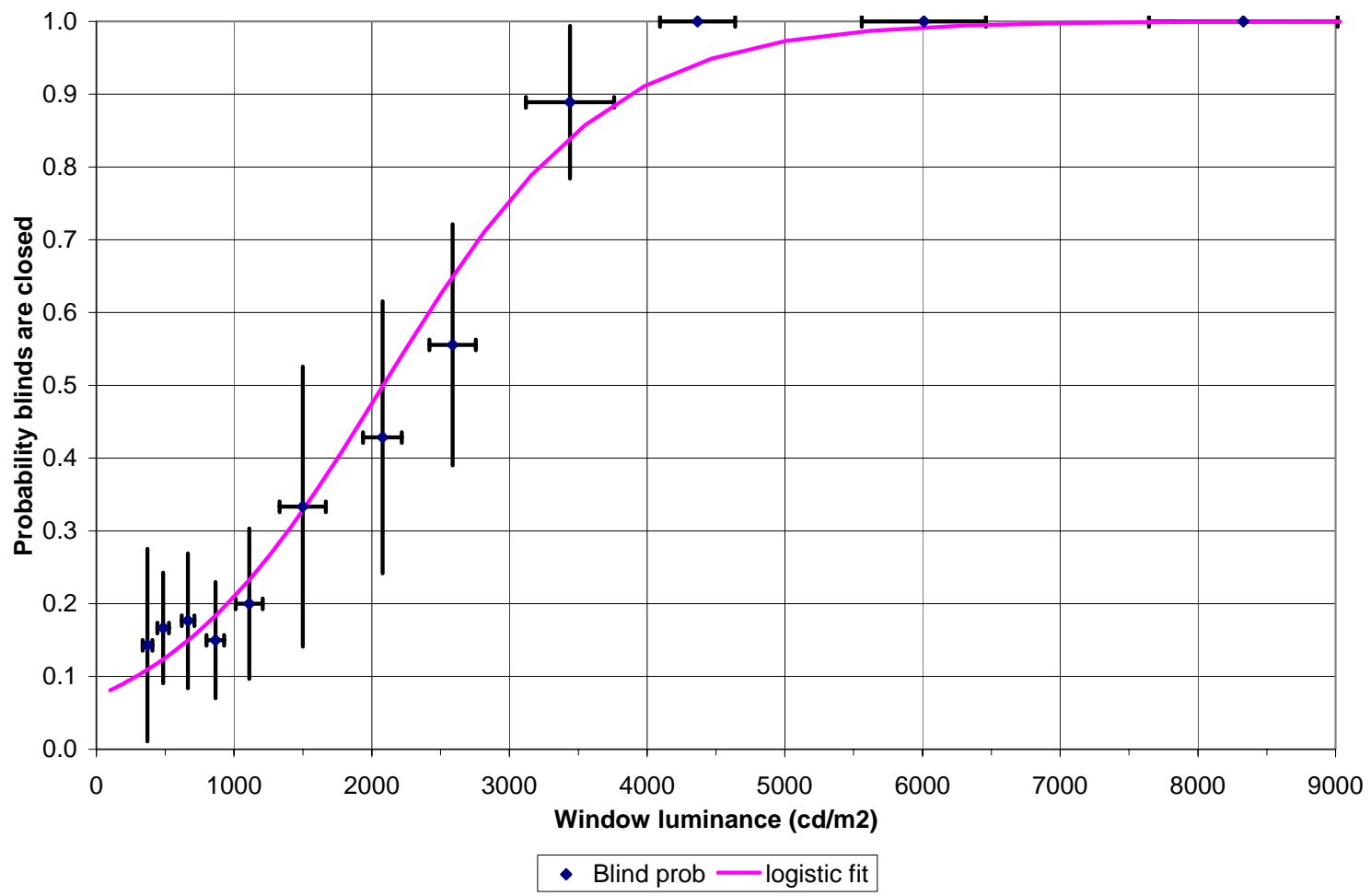

Fig. 7. Probability of closing blinds versus window luminance (mean and standard deviation) 
A second interesting finding was the high fraction of subjects who faced the window. Approximately $50 \%$ of the subjects using a laptop faced the window, and almost two-thirds of the subjects faced the window when they were not using a computer. This was despite the fact that the window was the most commonly cited glare source, and that $90 \%$ of the time blinds were deployed to reduce glare or brightness. We set the desktop computer work area facing the sidewall, as this orientation is expected to be less glaring. However, facing the window, or facing diagonally, prevents the sun from falling directly on the computer monitor. There is a tension between the desire to face the window and keep reflections off the monitor, and problems with glare and brightness. To the extent that electrochromics could control glare we would expect a higher proportion of people who would want a window and who would use it.

In this vein, it should be noted that more than half the subjects who replied felt that it would be desirable if the electrochromics could be dimmed even further than they were, which is consistent with the finding that excessive brightness and glare were the main factors that affected user satisfaction. The subjects who did not respond to the question about the desirable range of the electrochromics did not experience bright sky conditions, and presumably did not feel that they could make a judgment.

We had hypothesized that unstable skies might be disturbing and would result in more blind use and lower satisfaction. We derived a stability ratio which measured deviations from a linear trend to test this hypothesis. The stability ratio is high for cloudy and partly cloudy conditions, and generally low for clear sky conditions. In contradiction to our hypothesis, our results indicated that high stability ratios (unstable skies) were correlated to reduced blind use (see Table 13b). This result is not related to the overall light levels, as vertical illuminance is included as part of the fit. An explanation for this result will require further study.

Many of the independent and dependent variables are closely related or correlated to each other. This implies the need for caution in interpretations. For example, simple regressions show that blind use is negatively correlated to overall satisfaction, glare and reflection control Blind use is also correlated to the independent variables, primarily luminance related variables, which are included in the best fits of these subjective variable. Blind use is therefore most likely a related symptom, and not a cause, of the negative responses.

The large number of parameters, and the high degree of correlation between many of them, led to several cases where several different fits had nearly the same explanatory power. This is particularly true among the various window luminance measures, and it is likely that some of the variety of "best" fitting parameters is due to statistical chance. However, it is also likely that some of the variety is real. For example, satisfaction with the control of the windows and lighting was dependent upon the product of the window transmittance and the outdoor vertical illuminance, and not the window luminance. This computed variable is a direct physical measurement of the window's ability to control the daylighting, which can be judged by the change in tint of the window. It is not exactly equivalent to window luminance because of the difference in the field of the view for the window luminance and the outdoor vertical illuminance measurements. Window luminance does correlate to outdoor vertical illuminance, and to the subject's perception of the ability to control the windows and lights, but it is inferior to the computed variable in its predictive power and significance.

There is also a significant difference between window luminances and illuminances averaged over a session, and the "restricted" values averaged only over the period before blinds were pulled. It is obvious that the restricted luminances are the appropriate parameters to evaluate blind use, but it was a surprise to find that 7 of the remaining 10 fits in Table $13 \mathrm{~b}$ were directly correlated to a restricted luminance value. Only the fit to light control was clearly more related to the session averages than the restricted averages. The restricted averages are ideally the same as the session averages whenever the blinds were not used, which was 83 out of 129 sessions. For most of the remaining 46 sessions, the restricted values of the luminances and illuminances were considerably higher than the session averages. For example, the restricted and average window luminance was about $920 \mathrm{~cd} / \mathrm{m}^{2}$ for sessions where the blinds weren't drawn. When the blinds were drawn the restricted luminances were $2885 \mathrm{~cd} / \mathrm{m}^{2}$, while the unrestricted luminances were $1435 \mathrm{~cd} / \mathrm{m}^{2}$. In general, the session averages predict only a small change in satisfaction and most of the other dependent variables when the blinds are pulled. The restricted averages lead to larger predicted changes, which is consistent with what was found. Blind use as a binary variable was not as good a fitting parameter as the restricted luminances, so it appears that subjects may be judging the room on the maximum luminances rather than the averages over the entire session. 
As a caveat it should also be noted that our "best" fits were best only within the sample of fits that we examined. We may not have measured the most appropriate variables, or we may have not measured them as accurately as needed.

\section{Conclusions}

Subjects working in a private office on their typical office tasks rated the automated and semiautomated electrochromic windows (visible transmittance range of approximately 3-60\%) higher than the reference condition where the window had a fixed transmittance of $60 \%$. Our test electrochromic windows had a faint yellow tint when fully bleached, and a deep blue tint when fully darkened, but only two subjects had significant negative reactions to the color. The remaining subjects were not disturbed by window color. Analysis of subject responses and physical data collected during the work sessions showed that the controlled electrochromic windows reduced the incidence of glare compared to working under the reference condition. Blind use was non-linearly related to window luminance and was significantly less with the operable electrochromic window. Electric lighting use was slightly increased with the operable electrochromic window, but this in part may have been because the reference mode allowed the subjects to directly turn off the lights, while the operable modes did not. Further work is needed to develop control algorithms that maintain satisfaction while allowing the energy saving potential of electrochromic windows to be fully realized.

\section{Acknowledgments}

We are indebted to our LBNL colleagues Dennis DiBartolomeo, Mehry Yazdanian, Howdy Goudy, Chuck Hambelton, Steve Marsh, and Judy Lai. We would also like to acknowledge in-kind contributions from SAGE Electrochromics, Inc., Tom Mifflin at Wausau Window and Wall Systems and from LiteControl, Inc. This work was supported by the California Energy Commission through its Public Interest Energy Research Program and by the Assistant Secretary for Energy Efficiency and Renewable Energy, Office of Building Technology, State and Community Programs, Office of Building Research and Standards of the U.S. Department of Energy under Contract No. DE-AC03-76SF00098.

\section{References}

[1] M. Moeck, E.S. Lee, M.D. Rubin, R.T. Sullivan and S.E. Selkowitz, "Visual quality assessment of electrochromic and conventional glazings", Solar Energy Materials \& Solar Cells 54(1998):157-164.

[2] E.S. Lee and D.L. DiBartolomeo, "Application issues for large-area electrochromic windows in commercial buildings", Solar Energy Materials \& Solar Cells 71(2002):465-491.

[3] A.D. Tenner, L. Zonneveldt, "Switchable Facades and Visual Comfort", Proceedings Right Light 5, Nice, May 29-31, 2002.

[4] M. Zinzi, "Office worker preferences of electrochromic windows: a pilot study", Building and Environment, in press, 2006.

[5] E.S. Lee, D.L. DiBartolomeo, S.E. Selkowitz, "Daylighting control performance of a thin-film ceramic electrochromic window: field study results", Energy and Buildings 38(2006):30-44.

[6] IEA Task 21, "Monitoring Procedures for the Assessment of Daylighting Performance of Buildings", Feb. 2001.

[7] E. Vine, E. Lee, R. Clear, D. DiBartolomeo, and S. Selkowitz, "Office worker response to an automated venetian blind and electric lighting system: a pilot study", Energy and Buildings 28(1998):205-218.

[8] J.H. Zar, "Biostatistical Analysis, 2nd edition", Prentice Hall, N.J., 1984.

[9] P. Chauvel, J.B. Collins, R. Dogniaux, J. Longmore, "Glare from windows: current views of the problem", LR\&T 14(1):31-46, 1982.

[10] “JMP Statistics and Graphics Guide, version 4", SAS Institute Inc., Cary, NC, US, 2000. 


\section{Appendix: Questionnaire}

\section{PART A: BACKGROUND INFORMATION}

A1) Please enter your session code number here:

A2) What is your gender?

a) Male

b) Female

A3) How old are you?

a) Less than 20

b) $20-29$

c) $30-39$

d) 40 - 49

e) 50 - 59

f) 60 or over

A4) Do you wear glasses when doing office work?

a) No

b) Yes

A5) Are you color blind?

a) No

b) Yes, Red-Green / Blue-Yellow. (please choose one)

c) I am not sure.

A6) Which of the following best describes your work?

a) Management

b) Clerical

c) Technical/Research

d) Other. Please specify

A7a) Where you normally work, do you have a view of a window while working?

a) No

b) Yes

A7b) If yes, do you have a scenic view?

a) No

b) Yes

A8) Are you right handed?

a) No

b) Yes

A9) What color are your eyes?

a) Brown

b) Blue and others

---End of Part A ----------- 


\section{PART B: ATTITUDINAL SURVEY}

B1) Please assign a rating from 1 to 5 for the importance of the following items in making a pleasant and productive office environment, with 1 being the least important and 5 being the most important.

Unimportant

$1 \quad 2$

Very Importan

a) Good temperature Control

|----|----|----|----|----|----|----|----|----|----|----|----|----|----|----|----|

b) Good lighting

|----|----|----|----|----|----|----|----|----|----|----|----|----|----|----|----|

c) Windows

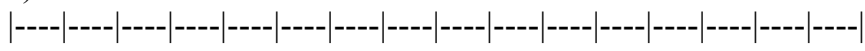

d) A view

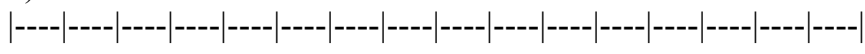

e) Comfortable (ergonomics) furniture

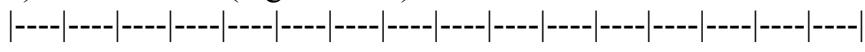

f) The latest computer/ operating system

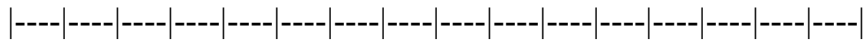

g) Privacy

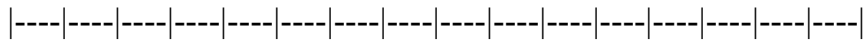

h) No noise

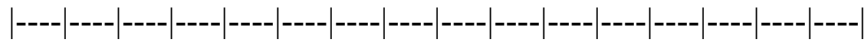

i) Controllable lights or windows

|----|----|----|----|----|----|----|----|----|----|----|----|----|----|----|----|

j) An attractive environment

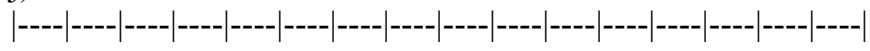

k) A good computer monitor

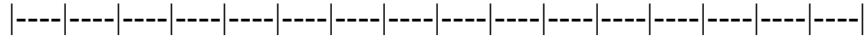

1) Other (specify)

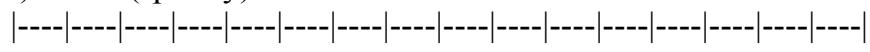


B2) Please assign a rating from 1 to 5 for your sensitivity to the following items, with 1 being not sensitive, 3 being moderately sensitive, and 5 being very sensitive.

Least Moderately Very

Sensitive

Sensitive Sensitive

a) Glare

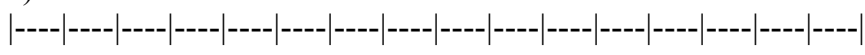

b) Cold

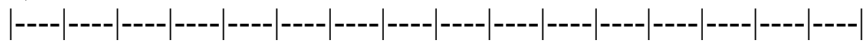

c) Heat

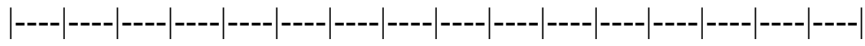

d) Gloominess

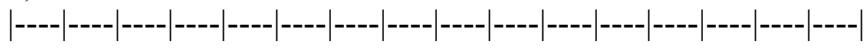

e) Noise

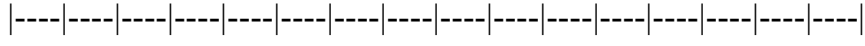

f) Visual distraction

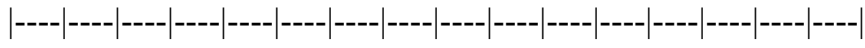

B3) When you perform your work tasks, what is your preferred light level in your workspace?

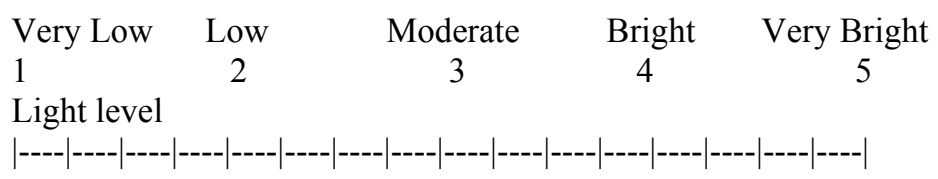

-End of Part B

PART E: SESSION 3 (Parts $C$ and D are identical to Part E except they did not include questions E12 through E15)

E1) Please enter your session code number here:

E2) During this session, what percentage of your time was spent on each of the following tasks?

Task Percent

Reading

Computer

Writing (by hand)

Telephone

Other (please specify)

$\begin{array}{r}\% \\ \% \% \\ \% \\ \% \\ \hline \% \\ \hline\end{array}$

E3) During this session, what percent of your time were you facing the following directions:

Task Percent

Sidewall

Window

Door

Other (please specify)

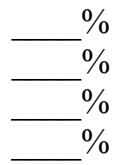

E4) Please assign a rating from 1 to 5 with the following lighting/thermal conditions of the test room during the past hour. 

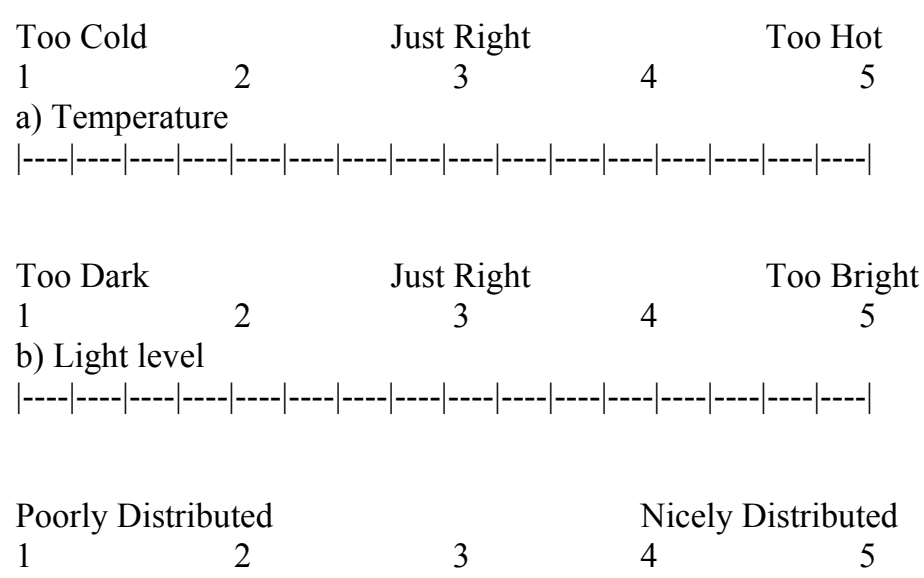

c) Lighting distribution
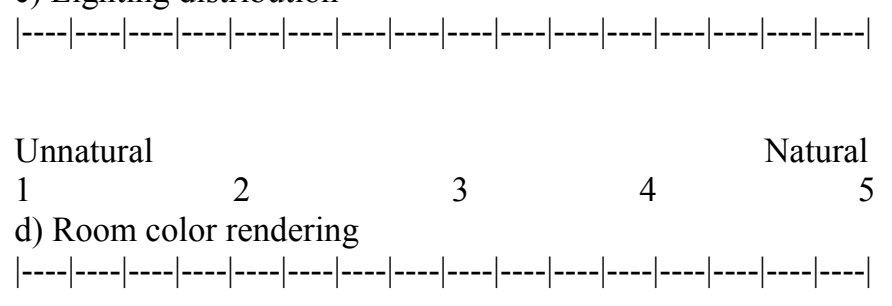

E5a) Please rate the level of glare sensation in your workspace during the past hour.

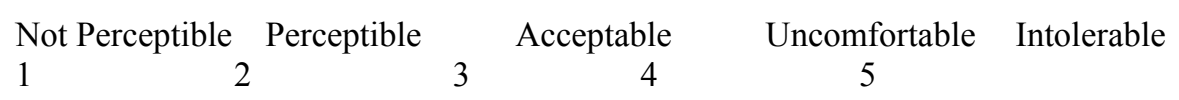

Chare cesarion

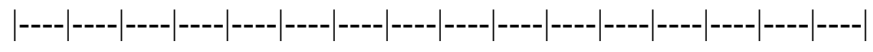

E5b) If you perceived glare sensation during the past hour; please indicate the source of the glare. (please check all that apply)
a) Window
b) Ceiling light
c) Wall surfaces
d) Reflections on the computer screen
e) Other (please specify)

E6) Please assign a rating from 1 to 5 for your satisfaction with the following attributes of the electrochromic window control system during the past hour, with 1 being very dissatisfied, 3 being just satisfied, and 5 being very satisfied.

\begin{tabular}{lllll} 
Very & Not & Just & Satisfied & \multicolumn{2}{l}{ Very } \\
Dissatisfied & Satisfied & Satisfied & & Satisfied \\
1 & 2 & 3 & 4 & 5
\end{tabular}

a) Light level control

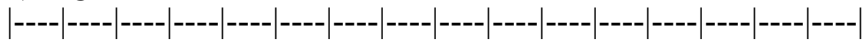

b) Glare control

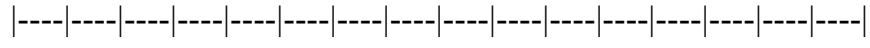

c) Control of reflections on computer monitor

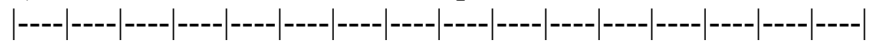


d) Temperature control

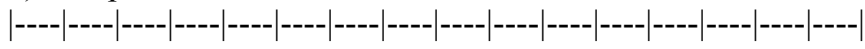

e) View

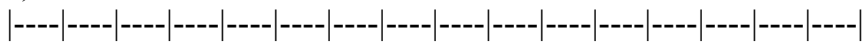

f) Ability to control windows/lighting

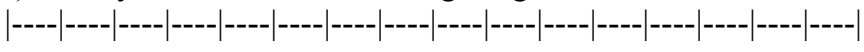

g) Other (specify)

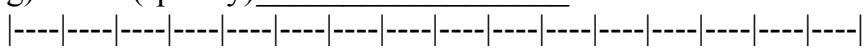

E7) Overall, how satisfied are you with the window control system in this session?

$\begin{array}{lllll}\text { Very } & \text { Not } & \text { Just } & \text { Satisfied } & \text { Very } \\ \text { Dissatisfied } & \text { Satisfied } & \text { Satisfied } & & \text { Satisfied } \\ 1 & 2 & 3 & 4 & 5\end{array}$

Overall Satisfaction

|----|----|----|----|----|----|----|----|----|----|----|----|----|----|----|----|

E8) If the window system in this session was installed in a room without a scenic view, how would you have rated it?

\begin{tabular}{lllll} 
Very & Not & Just & Satisfied & \multicolumn{2}{c}{ Very } \\
Dissatisfied & Satisfied & Satisfied & & \multicolumn{2}{c}{ Satisfied } \\
1 & 2 & 3 & 4 & 5 \\
Satisfaction (no view) & & & \\
|----|----|----|----|----|----|----|----|----|---|----|---|----|----|----|----|
\end{tabular}

E9a) Did you use window blinds in the past hour?

a) Yes

b) No

E9b) If yes, why did you deploy your window blinds? (please check all that apply)

a) To reduce glare from daylight/sunlight

b) To reduce the overall brightness of the room

c) To increase visual privacy

d) To reduce the heat from the sun

e) To reduce cold draft from the window

f) To decrease the level of visual stimulus from the outside

g) Other (please specify)

E10) Please add any additional comments (e.g. window operation, lighting, temperature, visibility, comfort, etc.) about this test session in the space provided below.

E11) Where did you put your computer in the past three sessions?

a) Window wall

b) Side wall

c) Other (please specify) 
E12) In the past three sessions, you have experienced three window control modes, which window control mode is the most desirable to have in an office, and which is the least desirable?

The MOST desirable window control mode is session \#

The LEAST desirable window control mode is session \#

E13) Please assign a rating from 1 to 5 for your satisfaction with the following attributes of the electrochromic windows, with 1 being very dissatisfied, 3 being just satisfied, and 5 being very satisfied.

\begin{tabular}{lllcl} 
Very & Not & Just & Satisfied & Very \\
Dissatisfied & Satisfied & Satisfied & \multicolumn{2}{c}{ Satisfied } \\
1 & 2 & 3 & 4 & 5
\end{tabular}

a) Window appearance

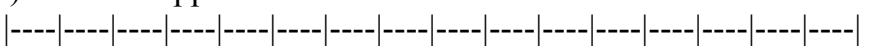

b) Time to lighten/darken

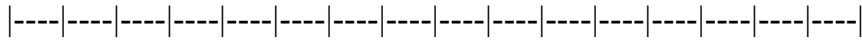

c) Color of window

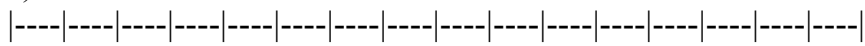

d) Other (specify)

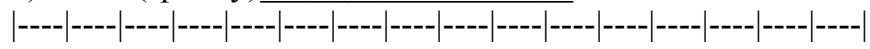

E14) Please assign a rating from 1 to 5 for your OVERALL satisfaction with the electrochromic windows, with 1 being very dissatisfied, 3 being just satisfied, and 5 being very satisfied.

\begin{tabular}{lllll} 
Very & Not & Just & Satisfied & Very \\
Dissatisfied & Satisfied & Satisfied & & \multicolumn{2}{c}{ Satisfied } \\
1 & 2 & 3 & 4 & 5 \\
Overall Satisfaction & & & \\
|----|----|----|----|----|----|----|----|----|----|----|----|----|----|----|----|
\end{tabular}

E15) Would you be more satisfied with the electrochromic windows if they could darken more than they currently do?

a) Yes

b) $\mathrm{No}$

--End of Part E-

\section{PART F: QUESTIONNAIRE USABILITY \& RESEARCH PROCEDURE}

Please help us improve the questionnaire and research protocol by giving your comments and suggestions in the following categories:

F1) Overall Experience

F2) Questionnaire usability (issues that were not address in the questionnaire, understanding of questions, etc.)

F3) Experimental procedure 